\begin{tabular}{|l|l|l|l|l|l|}
\hline MUNIBE Antropologia-Arkeologia & $\mathrm{n}^{\circ} 66$ & $327-346$ & DONOSTIA & 2015 & ISSN 1132-2217 • eISSN 2172-4555 \\
\hline
\end{tabular}

\title{
Exhumación, identificación y causa de muerte en 1936 de los restos humanos recuperados en la sima El Raso de Urbasa (Navarra)
}

\author{
Exhumation, identification and cause of death in 1936 of the \\ human remains recuperated in the chasm El Raso de Urbasa (Navarre)
}

PALABRAS CLAVES: Exhumación, Antropología forense, Carroñeo, ADN, Fosa común.

GAKO-HITZAK: Deshobiraketa, Auzitegiko antropologia, Txakurren hortz-markak, ADNa, Hobi komuna.

KEY WORDS: Exhumation, Forensic anthropology, Dogs Scavenger, DNA, Mass grave.

\begin{abstract}
Lourdes HERRASTI(1), Luis RÍOS(1), Lorena PÉREZ DE LA IGLESIA(1), Miriam BAETA(2), Carolina NUÑEZ(2), Marian MARTíNEZ DE PANCORBO(2), Pedro CASTAÑOS ${ }^{(3)}$, Jone CASTAÑOS ${ }^{(4)}$ \& Francisco ETXEBERRIA ${ }^{(1,5)}$
\end{abstract}

\section{RESUMEN}

Se presentan, en este caso, los resultados de la investigación llevada a cabo en una sima de Urbasa (Navarra), a la que fueron arrojados los cadáveres de diez personas asesinadas en 1936, con el propósito de ocultar el crimen, durante la Guerra Civil española. Se trata de población civil, que fue asesinada con carácter extrajudicial. Como aspecto tafonómico a destacar, los restos humanos presentan marcas de carroñeo provocado por perros que cayeron o fueron echados a la sima en la misma época. A partir del análisis histórico, arqueológico, antropológico y genético, se establece la identidad y la causa de muerte de estas víctimas como parte de las investigaciones desarrolladas en materia de Memoria Histórica. Las evidencias de carácter forense confirman los hechos conocidos históricamente con carácter objetivo, como evidencia del crimen cometido contra víctimas de población civil.

\section{LABURPENA}

1936an Espainiako Gerra Zibilean hil zituzten hamar pertsonen gorpuak Urbasako leize batera bota zituzten eta, orain, leize hartan egindako ikerketaren emaitzak aurkeztu dira. Tafonomia arloan, gorpuzkiek txakurrek eragindako markak dituztela nabarmendu beharreko alderdia da. Azterketa historiko, arkeologiko, antropologiko eta genetikoan oinarrituta, biktima horien identitatea eta heriotzaren kausa ezarri dira, Memoria Historikoaren esparruan garatutako ikerketen ildoan. Auzitegi-izaerako nabaritasunek modu objektiboan berresten dituzte historikoki ezagutzen diren gertakariak, biktima zibilen aurka egindako krimenaren froga gisa.

\section{ABSTRACT}

The exhumation of graves of the Spanish Civil War (1936-1939) and the Franco dictatorship until 1975 has meant something more than a task for experts in Forensic Archaeology and Anthropology.

Since 2000, more than 400 mass graves have been opened and about 8,000 skeletons have been recovered. This has raised public awareness about an injustice that was pending institutional recognition.

Faced with the oblivion imposed by fear during the dictatorship itself and which persists to this day, the 21st century saw the emergence of the conviction that the right to the truth is no longer individual and exclusive to the victims but pervades the whole of society and has become a collective issue. What is more, the movement in support of Historical Memory expands the discourse on Human Rights and reinforces civic and democratic values. That is why the investigation designed to clarify the facts relating to the repression in the Franco era is fundamental since the right to the truth and memory must be based on the parameters of objectivity and impartiality. That is why Forensic Archaeology, Forensic Anthropology and Forensic Pathology are acquiring substantial importance, which is recognised by the relatives of the victims and by the institutions.

To be able to carry out this exhumation work, the protocol followed is, on the whole, as follows: a) The existence of a legitimate interest in the exhumation by the relatives who have promoted it. b) The producing of a preliminary report of a technical nature. c) Exhumation using archaeological methodology and analysis of the remains. d) The drawing up of an expert report on the causes and circumstances of death.

(1) Departamento de Antropología. Sociedad de Ciencias Aranzadi. Alto de Zorroaga. 20014 Donostia-San Sebastián. antropologia@aranzadizientziak.org

(2) Grupo de Investigación Consolidado BIOMICs. Edificio CIEA "Lucio Lascaray". Universidad del País Vasco UPV/EHU. Avda. Miguel de Unamuno 3. 01006 Vitoria-Gasteiz. grupobiomics@gmail.com

(3) Sociedad de Ciencias Aranzadi. Centro Geo-Q. Santimami Auzoa 42. 48940 Leioa. pedrocastanos@yahoo.es

(4) Departamento de Estratigrafía y Paleontología Facultad de Ciencia y Tecnología, Universidad del País Vasco UPV/EHU. Apartado 644. 48080 Bilbao. jonecastanos@yahoo.es

(5) Medicina Legal y Forense. Facultad de Medicina y Odontología. Universidad del País Vasco UPV/EHU. Apartado 1599. 20014 Donostia-San

Sebastián. paco.etxeberria@ehu.es 
If we exclude the deterioration that appears in all the bodies as a result of the action of dogs, the state of preservation of the remains can be regarded as good, and that is why it has been possible to establish that all the victims were shot in the head by means of a firearm and were later thrown into the chasm. Furthermore, DNA tests have made it possible to establish the identity of nine of the ten victims, all of whom were males and who had resided in the area where the chasm is located.

The results of research carried out on a chasm in Urbasa, Navarre, where the bodies of ten people murdered in 1936 during the Spanish civil war were discarded, are presented. It is worth pointing out that taphonomy indicates that the human remains have scavenger marks made by dogs. As a part of investigations being carried out on matters of historical memory, historical, archaeological, anthropological and genetic analyses have enabled the identities and causes of death of these victims to be determined. Forensic evidence confirms well-known historical facts from an objective point of view and provides evidence of the crimes committed against civilian victims.

\section{1.- INTRODUCCIÓN Y ANTECEDENTES}

Desde el año 2000 se vienen desarrollando distintas acciones de investigación en justo reconocimiento de las víctimas de la Guerra Civil y de la dictadura franquista entre las que se encuentran la catalogación de fosas y la realización de exhumaciones (ETXEBERRIA, 2012). Fruto de la experiencia adquirida y de los protocolos que se han propuesto en este ámbito, llevamos a cabo la exhumación en la sima de El Raso (Navarra), en la que se han tenido en cuenta las siguientes cuestiones': a) Existencia del interés legítimo en la exhumación de los familiares que la han impulsado. b) Elaboración de un informe preliminar de carácter técnico. c) Exhumación y análisis de los restos. d) Elaboración de un informe pericial sobre las causas y circunstancias de su muerte.

De este modo, de conformidad a la solicitud cursada por D. Balbino García de Albizu, tras obtener el permiso del Gobierno de Navarra, en marzo de 2013 llevamos a cabo la exhumación de los restos humanos localizados en el interior de la sima de El Raso en Urbasa². Previamente, en julio de 2012, realizamos una visita al lugar con el fin de valorar la posibilidad de exhumar los restos, ya que se trata de una sima vertical cuyo acceso fue taponado por encargo de varios familiares sobre los años 50 .

Los hechos eran conocidos históricamente y habían sido recogidos por el historiador navarro José María Jimeno Jurio (AFAN, 2004).

\section{2.- LOCALIZACIÓN}

La sima de El Raso se sitúa en una amplia hondonada a la derecha de la carretera NA-7182 que atraviesa el raso de Urbasa, que se extiende desde el Palacio del Marqués de Andía hacia Zudaire y Estella. Coordenadas UTM: X 568.939. Y 4.740.150. Se trata de una cavidad natural con entrada vertical de unos $10 \mathrm{~m}$ que se abre en una sala es- paciosa de más de $40 \mathrm{~m}$ de anchura y que fue explorada por primera vez el año 1956 por miembros del Grupo de Espeleología de Estella. Según la información aportada por los espeleólogos, en el suelo de la sala vieron varios esqueletos humanos que presentaban ropas muy degradadas llamando la atención que uno de ellos estaba desplazado varios metros de la vertical ${ }^{3}$.

Los pastores de la zona conocían y corroboraron los hechos, esto es, el asesinato y posterior ocultación de los cuerpos pertenecientes a varios vecinos de Eulate en verano de 1936. Posteriormente, sobre el año 1956, familiares de Balbino García de Albizu cerraron la entrada a la sima con un enlosado y colocaron una lápida con los nombres de las víctimas que se conocía podían estar en la cavidad: Balbino García de Albizu, Gregorio García Larrambebere y Balbino Bados.

En fecha 23 de marzo de 2013 procedimos a la apertura de la cavidad practicando un orificio ajustado a las necesidades de acceso. En dicha inspección se verificó la existencia de restos humanos.

\section{3.- EXHUMACIÓN}

Entre los días 27 y 29 de marzo de 2013 realizamos la exhumación de un total de diez esqueletos que se encontraban en el fondo de la cavidad a $20 \mathrm{~m}$ de profundidad y sobre el suelo de piedras sueltas de caliza (Figura 1). Para ello instalamos un sistema de grúa ligera sobre la vertical de la sima accionada mediante generador eléctrico y otra vía secundaria de seguridad para los descensos y ascensos del equipo. Asimismo, instalamos luz eléctrica con abundantes focos con el fin de mejorar la visibilidad en el amplio espacio de la cavidad. La temperatura interior era constante en torno a los $12^{\circ} \mathrm{C}$, existiendo puntos de goteo dependiendo del régimen de precipitación exterior, que durante los días de exhumación fue lluvioso y frío.

\footnotetext{
1 Para ello se ha utilizado el protocolo en la Orden PRE/2568/2011, de 26 de septiembre, en relación a las exhumaciones de víctimas de la guerra civil y la dictadura

2 Previamente, en julio de 2012, realizamos una visita al lugar con el fin de valorar la posibilidad de exhumar los restos ya que se trata de una sima vertical cuyo acceso fue taponado por algunos de los familiares sobre los años 50. La exhumación fue realizada con el impulso de la Asociación de Familiares de Fusilados de Navarra bajo la coordinación de Balbino García de Albizu y Olga Alcega. Los análisis genéticos contaron con el apoyo económico de varios ayuntamientos de la comarca: Altsasua, Amescoa Baja, Aranarache, Etxarri Aranaz, Eulate, Larraona y Olazti. Dirección técnica: Fco. Etxeberria. Arqueología: Lourdes Herrasti. Jimi Jiménez. Almudena García-Rubio. Berta Martínez. Itxaso Martelo. Tito Aguirre. Asier Izaguirre. Sebastián Lasa. Gotzon Berjerandi. Rafael Zubiria. Pello Iraizoz. Patxi Areta. Antropología: Fco. Etxeberria. Luis Ríos. Claudio Albisu. Javier Iglesias. Fernando Serrulla. Genética: Miriam Baeta, Carolina Núñez. Marian Martínez de Pancorbo. Restos faunísticos: Pedro Castaños, Jone Castaños. Colaboradores: Javier Macaya. Roldán Jimeno. Olga Alcega. Javier Yaben. Koldo Pla. Joseba Ezeolaza, Juan Mª Txoperena, José Mª Pastor, Julia Ochoa y Ricardo Ugarte.

${ }^{3}$ El lugar fue visitado por miembros de Aranzadi el 12 de julio de 2012 realizando varias entrevistas que se graban en vídeo.
} 


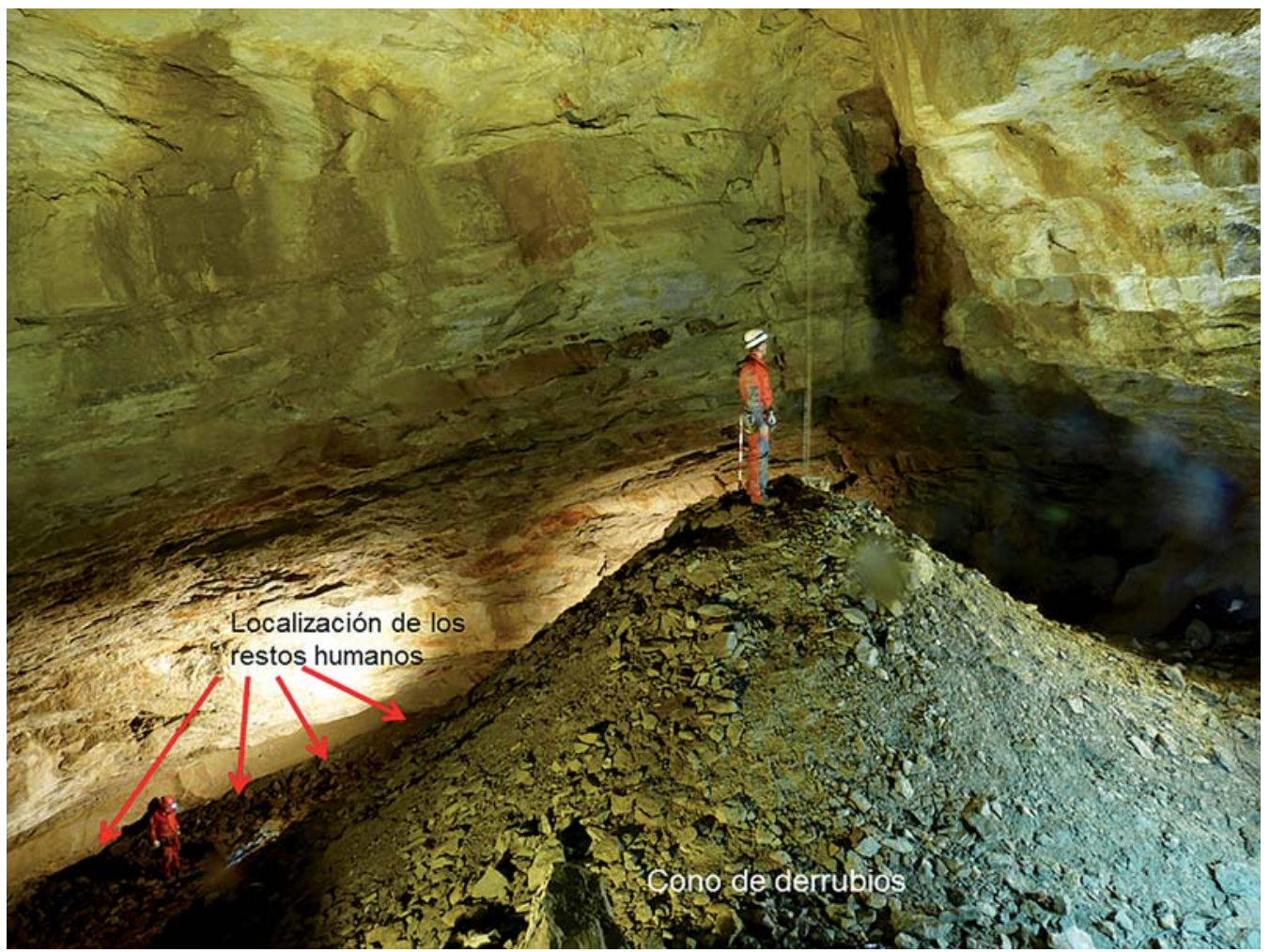

Fig. 1. Cono de derrubios al pie de la vertical de entrada a la sima. Al fondo, los restos humanos. / Debris cone into the chasm at the foot of the vertical entrance. The human remains are at the back.
Los cadáveres habrían sido arrojados por la vertical de la sima para rodar por el plano inclinado del cono de derrubios existente hasta el fondo de la misma y alcanzar casi el contacto con la pared (Figura 2 y 3). Al menos en dos casos algunos restos se encontraban dispersos en el plano inclinado, lo que da idea de que quedaron retenidos en este punto sin llegar al fondo.

En general los esqueletos presentaban conexiones anatómicas, si bien predominada una cierta dispersión

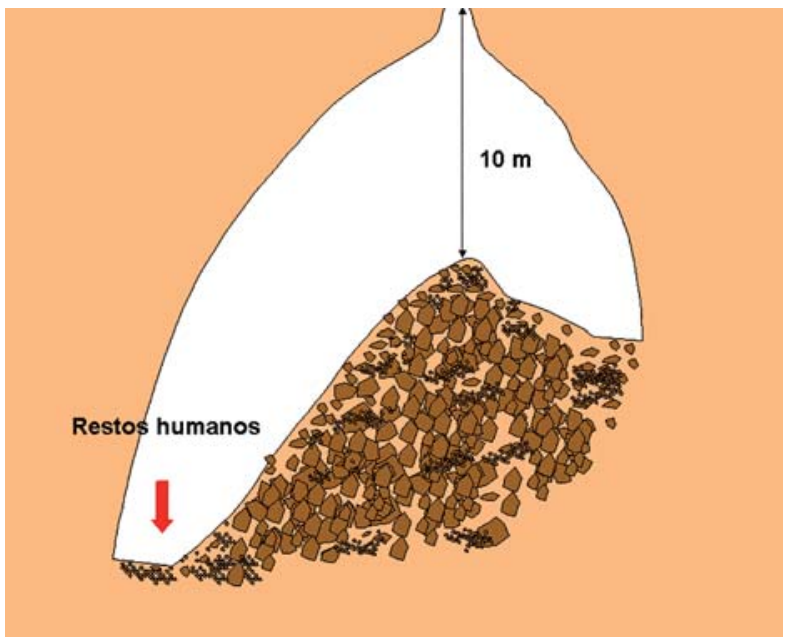

Fig. 2. Corte transversal de la sima en forma de campana. La flecha señala el lugar donde se encontraban los restos. / Bell-shaped cross section of the chasm. The arrow indicates the spot where the remains were found.

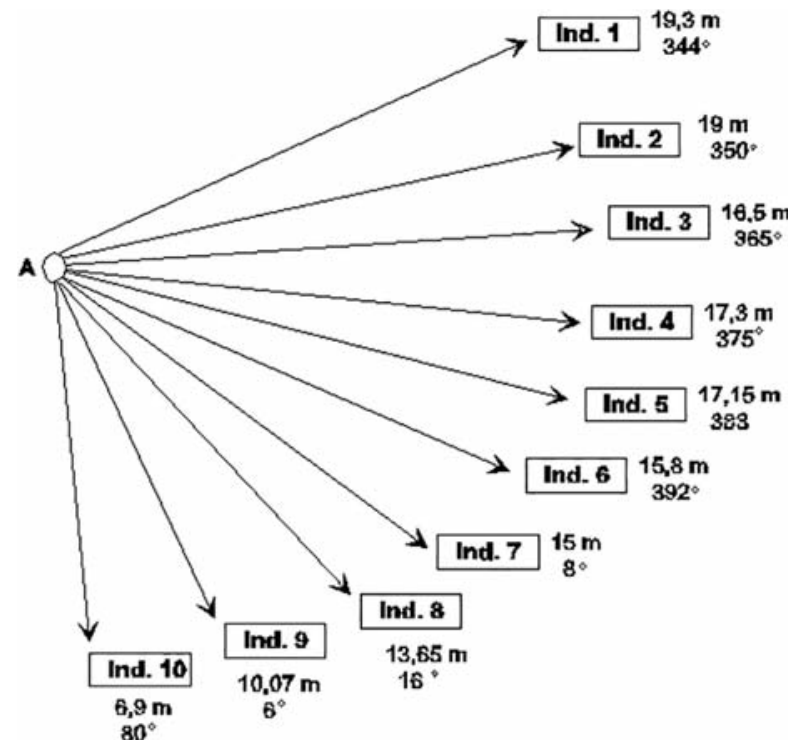

Fig. 3. Dispersión de los esqueletos en el cono de derrubios al fondo de la sima. / Distribution of the skeletons in the base of debris cone into the chasm.

como consecuencia de la putrefacción de los cadáveres in situ. En efecto, observamos la presencia de puparios así como un residuo de color negruzco correspondiente al putrílago procedente de las partes blandas del organismo y prendas de vestir que se encontraban mal conservadas. Además los restos humanos fueron alterados y diseminados por la acción de los perros, tal y como lo demuestran las marcas de carroñeo observadas. 
Los restos fueron agrupados en conjuntos o grupos de conformidad a lo observado in situ, conservando la relación topográfica de sus estructuras. Para ello fue necesario retirar varias toneladas de piedras de todos los tamaños que en algunos casos cubrían algunos de los huesos. Asimismo, en el interior de la cavidad localizamos un total de cinco esqueletos de perro, junto con abundantes coprolitos, como también otros restos óseos de caballo, cerdo y oveja (Figura 4). De hecho, uno de los aspectos más característicos de los restos humanos radica en que presentan huellas de carroñeo realizados en el interior de la cavidad por uno o varios de los perros que debieron llegar hasta ese punto cuando existían partes blandas en los cadáveres. Resulta difícil saber si los perros fueron arrojados intencionadamente o accedieron de forma accidental. Por otro lado, en el fondo de la sima localizamos una granada de piña completa ${ }^{4}$, que probablemente fue arrojada junto con los cadáveres.

Tras la documentación y fijación de las evidencias mediante fotografía, dibujo y vídeo, procedimos a extracción de los restos de forma ordenada.

\section{4.- ANÁLISIS DE LOS RESTOS HUMANOS}

Acorde a las exigencias de los protocolos nacionales e internacionales en esta materia, se mantuvo la cadena de custodia tanto de los restos humanos como de las evidencias materiales recuperadas en la exhumación. En la fase de campo o de exhumación se observaron las siguientes acciones: protección del lugar, observación, fijación, recolección de evidencias y envío al laboratorio. En la fase de laboratorio se procedió al análisis antropológico, análisis de patología y análisis genético. Con ello se trata de dar respuesta a las siguientes cuestiones de interés forense: identificación, causa de la muerte, etiología médico-legal, data del fallecimiento y circunstancias que rodearon a la muerte.

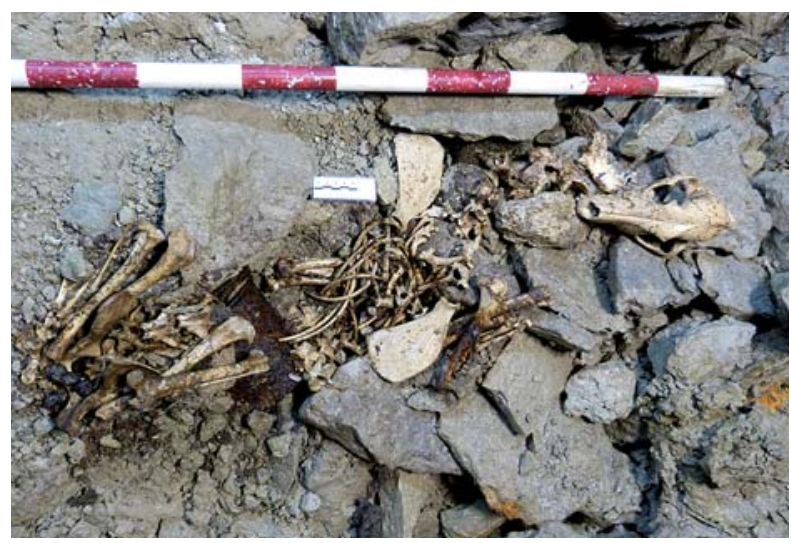

Fig. 4. Esqueleto completo del perro $n^{\circ} 1$. / Complete skeleton of dog no. 1 .
Los restos humanos fueron trasladados al laboratorio de Antropología Forense de la Universidad del País Vasco en su sede de San Sebastián, donde se ha realizado el estudio antropológico y el control de la cadena de custodia bajo la responsabilidad del Dr. Francisco Etxeberria. Para la determinación de la edad y el sexo se ha utilizado la metodología propuesta por BUIKSTRA y UBELAKER (1994). Para los aspectos de patología se han tenido en cuenta los principales tratados de Paleopatología, entre los que cabe señalar a ORTNER (2003), AUFDERHEIDE y RODRÍGUEZ-MARTÍN (1998) e ISIDRO y MALGOSA (2003), y en especial lo referente al trauma en WEDEL y GALLOWAY (2014), y KIMMERLE y BARAYBAR (2011). Los análisis genéticos fueron realizados en el laboratorio Biomics de la Universidad del País Vasco (UPV-EHU), bajo la dirección de la Dra. Marian Martínez de Pancorbo.

Una vez en el laboratorio, se realizó un tratamiento de limpieza y restauración para pasar posteriormente al análisis antropológico y de patología fotografiando las evidencias de mayor interés así como los objetos asociados a las osamentas, que fueron restaurados por Juan María Txoperena.

Finalmente, toda la investigación ha sido registrada, documentada y recogida en formato audiovisual y fotográfico, incluyendo la grabación de algunos de los testimonios.

\subsection{Descripción individualizada de los restos humanos}

En el interior de la cavidad se hallaron los restos pertenecientes a un total de diez personas:

\section{INDIVIDUO 1}

Individuo masculino adulto maduro, de edad superior a los 40 años. Como variante anatómica presenta una asimilación de la primera vértebra cervical o atlas en la base del cráneo (Figura 5). Asimismo, las vértebras cervicales C2 y C3 están soldadas conformando un bloque vertebral de carácter congénito (Figura 6). Por otro lado, el sacro presenta dehiscencia de los arcos posteriores. Los extremos distales de los fémures han desaparecido y los bordes de las diáfisis muestran signos evidentes de las mordidas de los cánidos.

Presenta evidentes signos de enfermedad degenerativa en la columna vertebral, como son osteofitos en los rebordes de los cuerpos lumbares y vértebras torácicas bajas. Muestra fracturas perimortem en costillas que, posiblemente, están relacionadas con la caída o precipitación del cadáver. Sin embargo, en el parietal izquierdo se observa la línea vertical de una fractura craneal antigua consolidada que alcanza la escama temporal. Asimismo, los

\footnotetext{
4 Tras cursar el correspondiente aviso a Policía Foral de Navarra, un equipo de la Guardia Civil procedió a su extracción y desactivación el día 29-03-2013.
} 


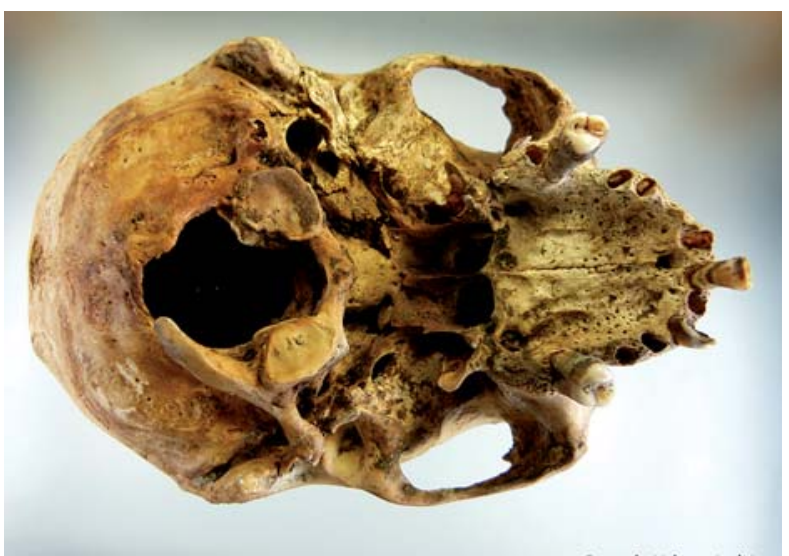

Fig. 5. Asimilación de la primera vértebra cervical a la base del cráneo. / Assimilation of the first cervical vertebra at the base of the skull.

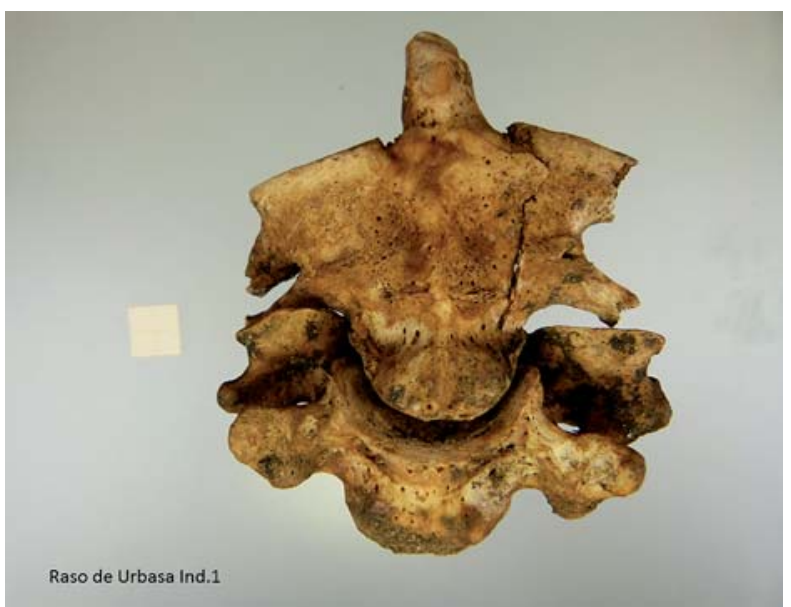

Fig. 6. Cuerpos vertebrales de $\mathrm{C} 2$ y $\mathrm{C} 3$ fusionados. / Fused $\mathrm{C} 2$ and $\mathrm{C} 3$ vertebral bodies.

huesos propios de la nariz están remodelados por la consolidación de una antigua fractura nasal. De lo anterior se deduce que este individuo sufrió un traumatismo en vida posiblemente por caída contra el suelo o impacto en el lado izquierdo de la cabeza, que le produjo ambas fracturas, que se resolvieron posteriormente de manera adecuada.

Como causa de muerte presenta una herida por arma de fuego con un claro recorte redondeado en el ángulo mandibular izquierdo (Figura 7), cuyo bisel interno indica que se trata del punto de entrada del disparo de $7 \mathrm{~mm}$ de diámetro que afectó a su paso a los arcos de las vértebras cervicales C2 y C3. La trayectoria, por lo tanto, fue de adelante atrás, de izquierda a derecha y ligeramente ascendente.

\section{INDIVIDUO 2}

Individuo masculino adulto joven, de edad en torno a los 30 años. Presenta huellas de carroñeo en epífisis de huesos largos.

La causa de la muerte viene determinada por el paso de un proyectil de arma de fuego en el cráneo. El orificio

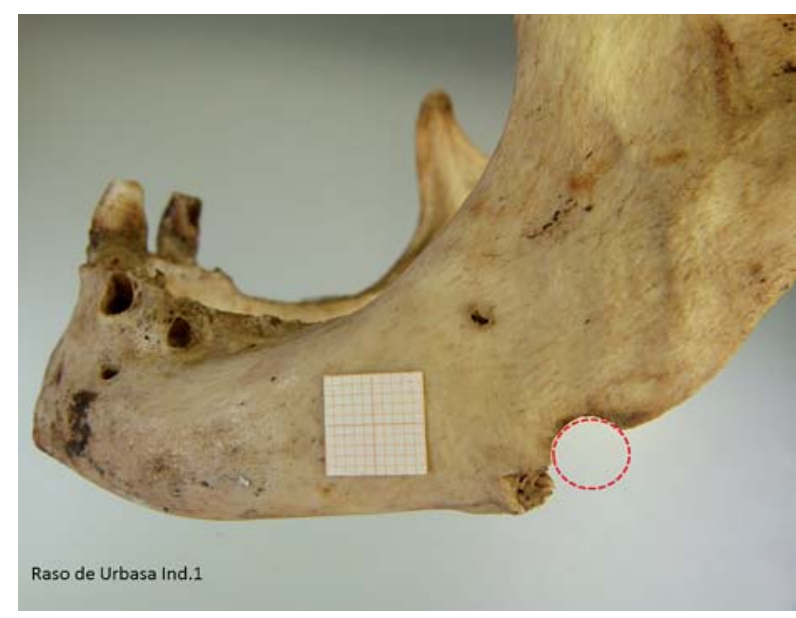

Fig. 7. Lesión por impacto de proyectil de arma de fuego. / Wound caused by the impact of a bullet from a firearm.

de entrada se sitúa en el arco superciliar izquierdo con un recorte de $8 \mathrm{~mm}$ de diámetro (Figura 8). Aunque no se conserva íntegra la calota craneana, es posible deducir que el proyectil salió por la parte posterior de la cabeza por el tipo de fractura. Así pues, el disparo fue de adelante atrás, de izquierda a derecha y descendente.

\section{INDIVIDUO 3}

Individuo de sexo masculino adulto joven, de edad superior a los 30 años. Huellas de carroñeo en los coxales, sacro y escápula izquierda. Osteofitos muy discretos en segmento torácico y lumbar de la columna vertebral. También presenta improntas de nódulos de Schmörl en la cara inferior de las vértebras dorsales D9, D10 y D11. Las costillas del lado izquierdo muestran fracturas perimortem que pueden ser atribuidas al impacto contra el fondo de la sima por la precipitación del cadáver.

En el cráneo se observa un orificio de entrada de proyectil de arma de fuego de $8 \mathrm{~mm}$ en la escama del tempo-

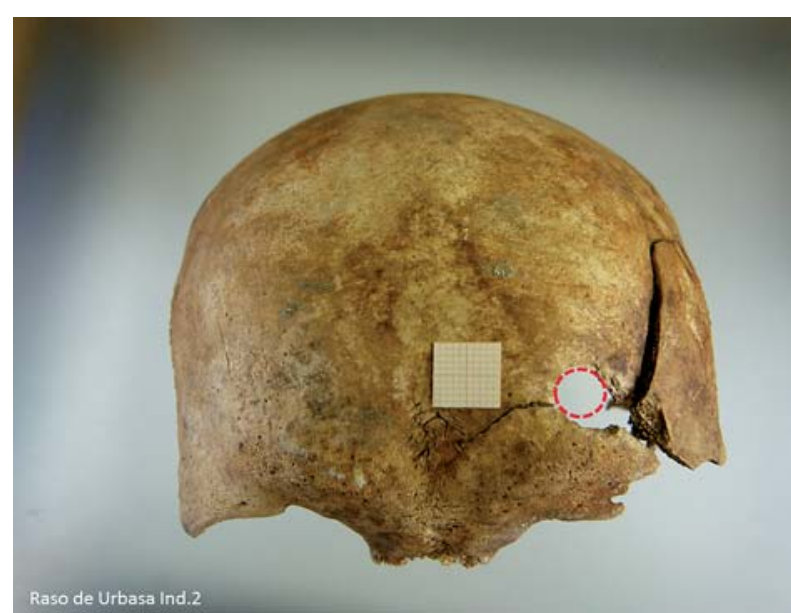

Fig. 8. Orificio circular de entrada de proyectil en la región frontal izquierda. / Circular entrance hole of the bullet in the left frontal region. 
ral izquierda (Figuras 9 y 10), y la salida se sitúa en el parietal y escama temporal derecha. La trayectoria del disparo fue de adelante atrás, de izquierda a derecha y subhorizontal.

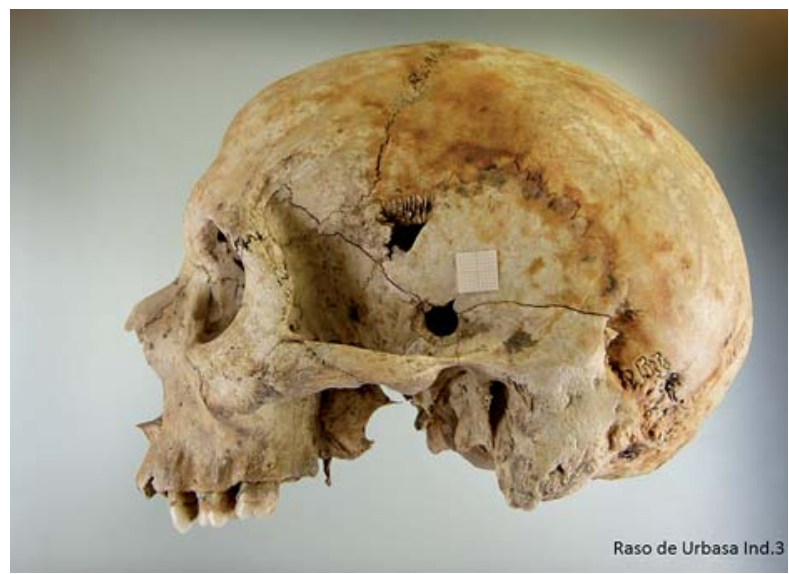

Fig. 9. Orificio de entrada de bala en la escama temporal izquierda. / Entrance hole of the bullet on the left temporal squama.

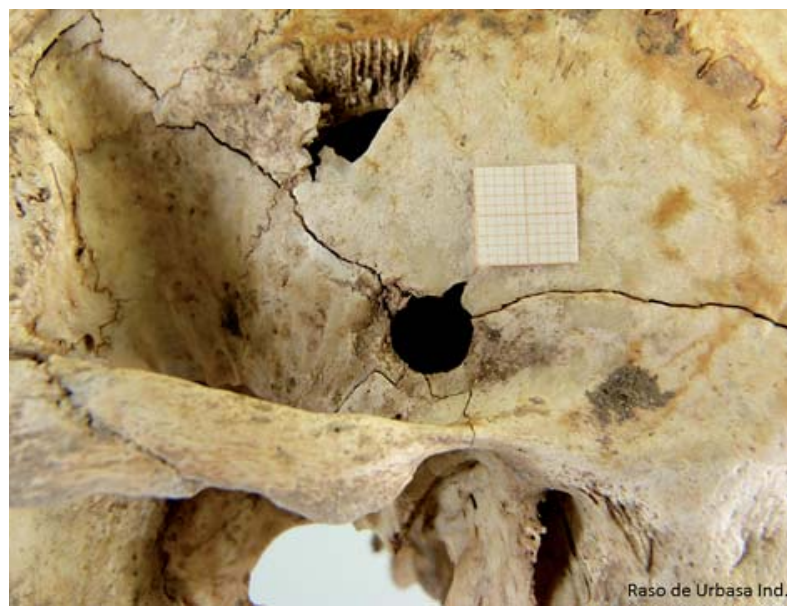

Fig. 10. Detalle del orificio de entrada. / Detail of the entrance hole.

\section{INDIVIDUO 4}

Individuo masculino adulto joven, de edad superior a los 27 años y de complexión robusta. La clavícula derecha está fracturada en la zona media en el perimortem. Los dos coxales están muy reducidos porque sufrieron carroñeo, así como también la epífisis del fémur derecho y escápula derecha. Osteofitos en las vértebras torácicas D8 y D9.

En relación con la causa de muerte se detectan signos de dos disparos. En uno de ellos, el proyectil entró por la parte alta del occipital, donde se localiza un orificio de entrada de $7 \mathrm{~mm}$ de diámetro (Figura 11). El proyectil atravesó el cráneo y salió por el mentón. La trayectoria del disparo fue de atrás adelante, perpendicular al cráneo y descendente. El otro disparo entró en el parietal derecho y salió por el izquierdo de forma subhorizontal (Figura 12).

Junto a los restos se recuperó un trozo de cremallera corta cerrada, de tipo jersey, en el área de la cintura es-

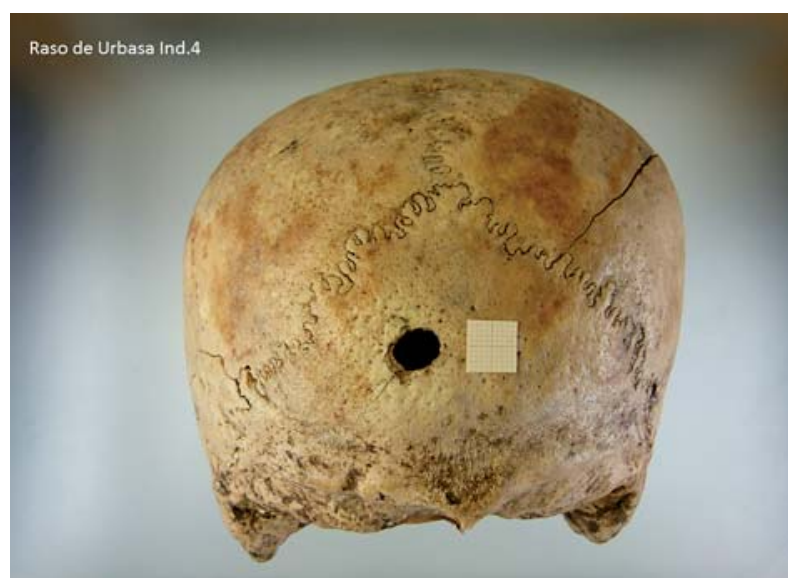

Fig. 11. Orificio de entrada en el occipital. Trayectoria de atrás adelante. / Entrance hole in the occipital bone. Path from the back to the front.

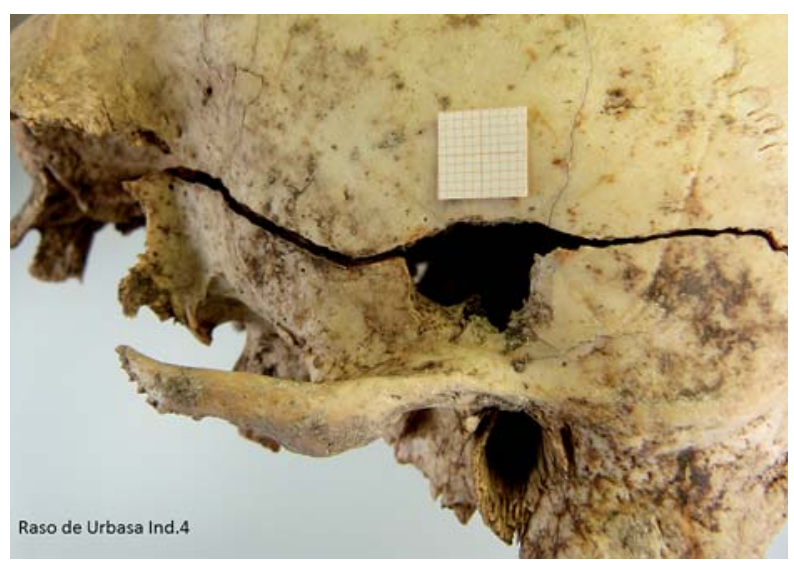

Fig. 12. Orificio de salida en el temporal izquierdo. Trayectoria de derecha a izquierda. / Exit hole on left temporal side. Path from right to left.

capular del individuo. Otro fragmento de cremallera estaba adherido a un trozo metálico de un cuerpo cilíndrico, que pudiera corresponder a una lata. Asimismo se ha hallado un botón de $20 \mathrm{~mm}$ de diámetro.

\section{INDIVIDUO 5}

Individuo masculino edad adulto joven, de 27 a 35 años. En el lado derecho del maxilar superior se observa una línea discontinua de fractura ósea consolidada que se sucede con una línea del arco cigomático como consecuencia una fractura por impacto directo en el rostro seguida de supervivencia (Figura 13).

En relación con la causa de muerte muestra una fractura de la base del cráneo, con un recorte oblicuo en el borde derecho del agujero magno y con arrancamiento del cóndilo izquierdo. En el malar izquierdo presenta un recorte redondo de $10 \mathrm{~mm}$ de diámetro con bisel externo. Se puede interpretar que el proyectil entró por el lado derecho de la base del cráneo y salió rompiendo el hueso cigomático izquierdo. Así pues la trayectoria del disparo fue de atrás adelante, de derecha a izquierda y ascendente. 


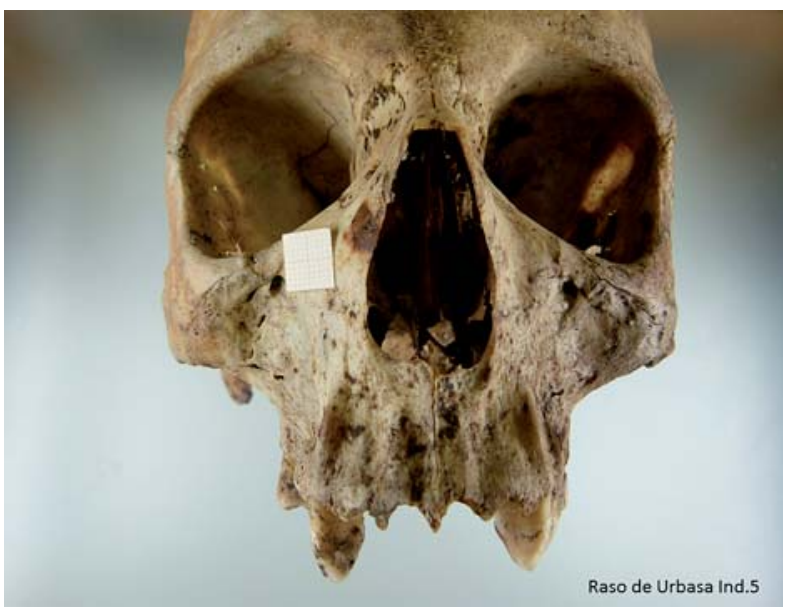

Fig. 13. Traumatismo en el maxilar superior derecho. Línea de fractura consolidada en el maxilar y el zigomático. / Injury in upper right jawbone. Consolidated fracture line in the jawbone and zygomatic arch.

Los objetos asociados a este individuo son: moneda de 5 céntimos de Alfonso XII (25 mm diámetro) (Figura 14); hebilla metálica rectangular de 55 por 42 mm; trabilla metálica de 35 por $27 \mathrm{~mm}$, que conserva restos de cuero; botón y elemento circular de $15 \mathrm{~mm}$ diámetro que pudiera corresponder a la rueda de un mechero; cuatro clavos; botón negro de 14 mm de diámetro; apliques de cuero pespunteado, que pudieran pertenecer a un zapato, y flecos de un fajín de color oscuro.

\section{INDIVIDUO 6}

Individuo masculino de edad adulta madura-senil superior a los 50 años (Figura 15), determinado por las lesiones degenerativas de la columna vertebral y calcificación de los cartílagos costales, además del tiroides y cricoides. Maxilares edéntulos por pérdida en vida de todos los dientes. Evidencias de carroñeo en epífisis proximal de húmero derecho y en las epífisis espinosas de las vértebras lumbares, así como en el acromion derecho y en el vértice inferior de ambas escápulas. Signos de enfermedad degenerativa en la columna vertebral con osteofitos en el reborde de los cuerpos vertebrales.

El cráneo está multifragmentado a consecuencia del paso de dos proyectiles de arma de fuego y a la dispersión

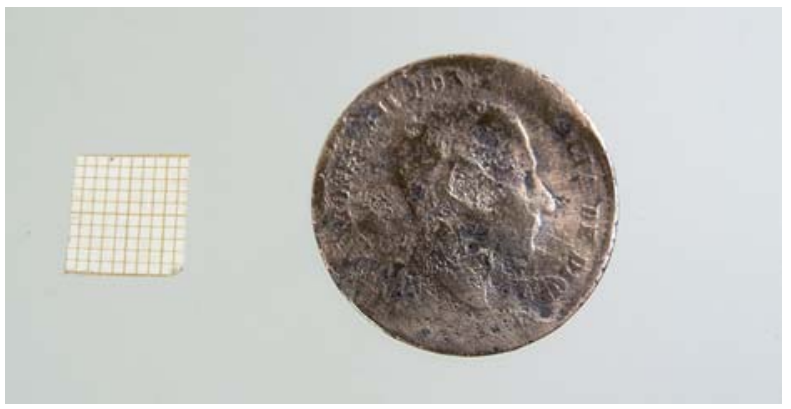

Fig. 14. Moneda restaurada. / Restored coin

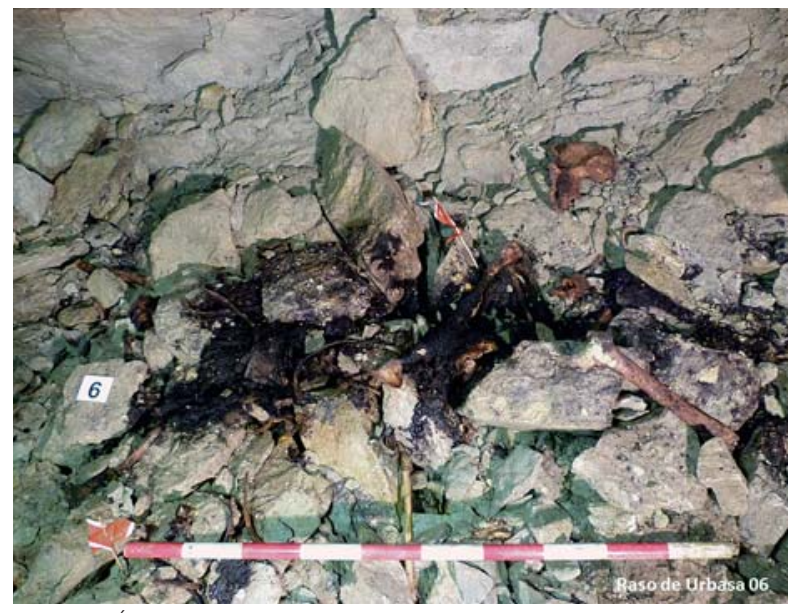

Fig. 15. Área de mayor concentración de los restos del Individuo 6. / Area of greatest concentration of the remains of Individual 6 .

de los fragmentos por la acción de los perros. El orificio de entrada es visible en la mitad izquierda del occipital, junto a la sutura lambda. El proyectil salió por el área de la sien izquierda del frontal. La trayectoria del disparo fue, por lo tanto, de atrás adelante, por el lado izquierdo y ascendente. El otro orificio de entrada se localiza en la región frontal entre los arcos superciliares y el proyectil no llegó a salir de la cavidad craneal, quedando parte del blindaje impactado contra la tabla interna del parietal izquierdo (Figuras 16 y 17). La trayectoria del disparo fue de delante atrás, de derecha a izquierda y subhorizontal.

Como elementos asociados a este individuo se han recuperado: fragmentos de tela negra que parece una camisa con botones blancos; tela negra con otra trama hallada en la zona del cuello; tela de jersey de lana de color oscuro sobre el sacro. Bajo estos últimos restos de tela se localizó un proyectil de arma de fuego de $9 \mathrm{~mm}$ de diámetro y $18 \mathrm{~mm}$ de longitud (Figura 18).

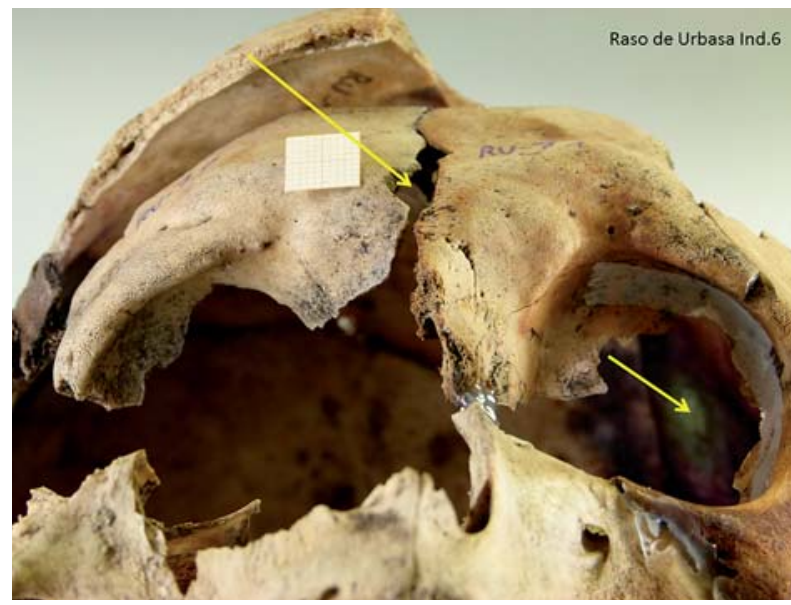

Fig. 16. Trayectoria del disparo, que entró por el frontal y quedó impactado en cara interna del parietal. / Path of the shot, which entered through the frontal region and became lodged on the inside of the parietal bone. 


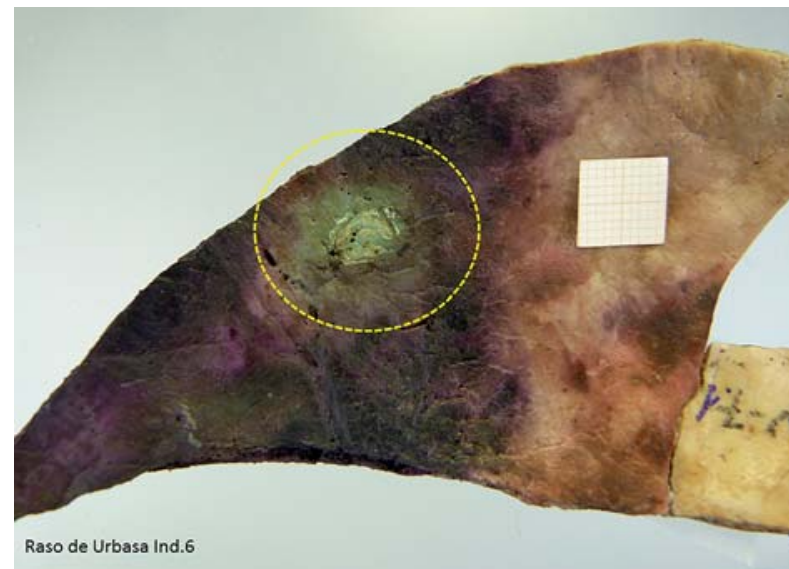

Fig. 17. Cara interna de fragmento craneal con mancha verde de óxido de cobre, antes de la recomposición del cráneo. / Inside of the cranial fragment with a green copper oxide stain before the skull was reconstituted.

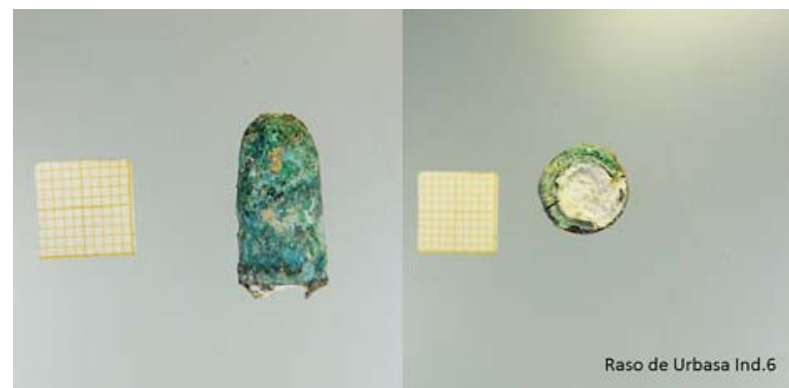

Fig. 18. Proyectil de $9 \mathrm{~mm}$ de diámetro. / A 9 mm-diameter bullet.

\section{INDIVIDUO 7}

Individuo varón de edad adulto joven-maduro, superior a los 30 años. Varias costillas del lado derecho presentan fracturas perimortem, probablemente relacionadas con la precipitación del cadáver en la sima. Como variante anatómica, el arco vertebral de la primera vértebra cervical presenta una falta de fusión del arco posterior.

Para la interpretación de la causa de muerte, se puede establecer la trayectoria del disparo con entrada en el parietal izquierdo y salida por la rama mandibular derecha, de atrás adelante, de izquierda a derecha y descendente.

Objetos asociados: mechero de mecha (Figura 19); proyectil de $9 \mathrm{~mm}$ de diámetro y $17 \mathrm{~mm}$ de longitud deformado (Figura 20). En el entorno de los Individuos 7 y 8 se han recuperado una serie de objetos: cinco botones metálicos, dos pasadores con tela de mil rayas; dos fragmentos de cuerda de hilo retorcido; tres botones de nácar; fragmento metálico de cobre con tela; gemelos metálicos compuestos de dos bolas esféricas de $10 \mathrm{~mm}$ de diámetro unidos con una pequeña argolla a una varilla metálica de $15 \mathrm{~mm}$ (Figura 21); lapicero de $82 \mathrm{~mm}$ de longitud de cuerpo poligonal y $7 \mathrm{~mm}$ de diámetro de color azul con capuchón de tipo cónico de 26 mm de longitud (Figura 22).

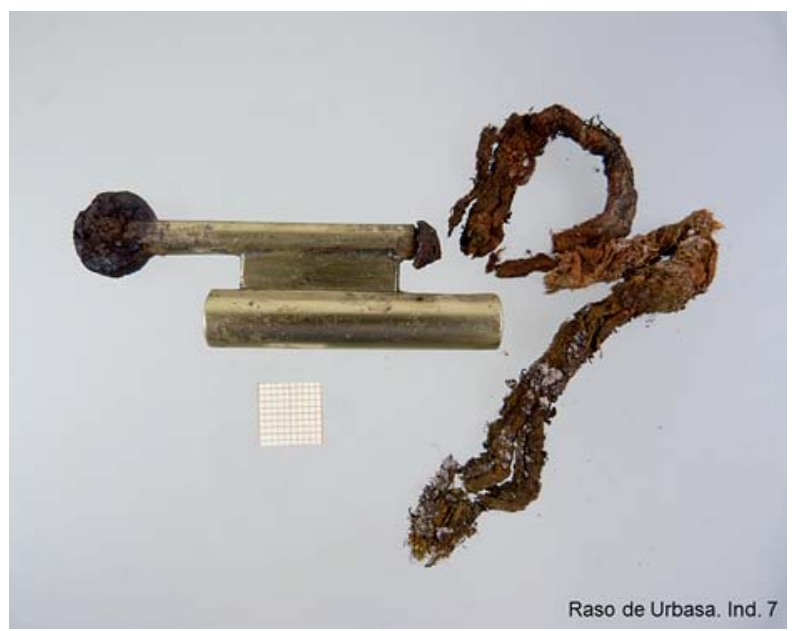

Fig. 19. Mechero y mecha restaurados. / Restored lighter and wick.

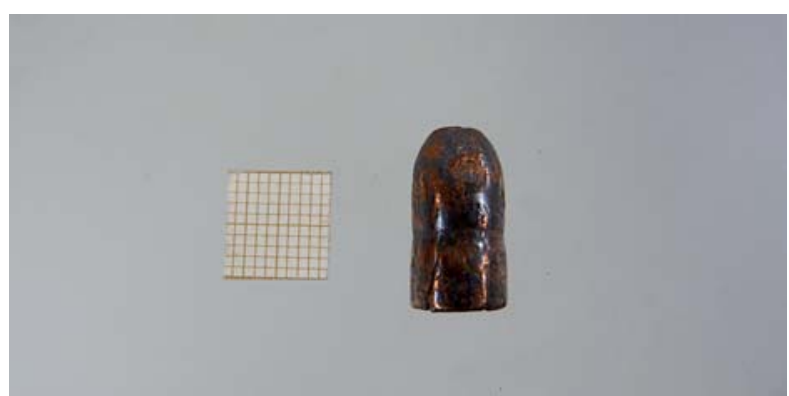

Fig. 20. Proyectil de $9 \mathrm{~mm}$ de diámetro tras la restauración. / A 9 mm-diameter bullet following restoration.

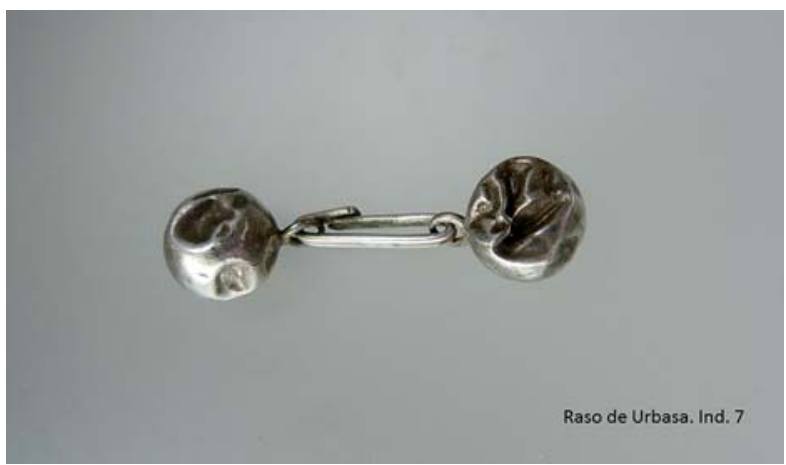

Fig. 21. Gemelos restaurados. / Restored cufflinks.

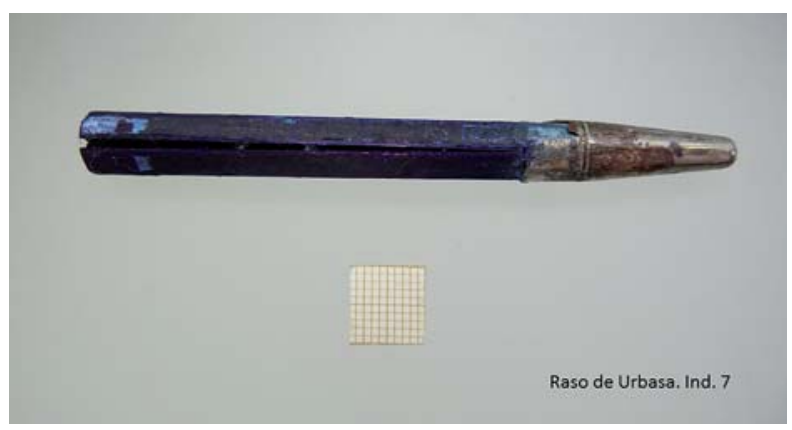

Fig. 22. Lapicero restaurado. / Restored propelling pencil. 


\section{INDIVIDUO 8}

Individuo masculino adulto joven, de edad superior a los 27 años. Vértebras lumbares afectadas por carroñeo.

Como causa de muerte en el parietal izquierdo muestra un orificio de entrada de $7 \mathrm{~mm}$ de proyectil de arma de fuego (Figura 23). En el parietal derecho se localiza el orificio de salida con un bisel exterior por la rotura (Figura 24). La trayectoria del disparo fue de adelante a atrás, de izquierda a derecha y horizontal.

Objetos asociados: Ilave metálica de $45 \mathrm{~mm}$ de longitud y la cabeza de $20 \mathrm{~mm}$ el diámetro exterior y $9 \mathrm{~mm}$ en el agujero interior, que se puede interpretar como de una caja o de un armario; suela de zapato claveteada incompleta de $53 \mathrm{~mm}$ de anchura y longitud el tacón y $38 \mathrm{~mm}$ en la parte más estrecha; presilla de cuero o parte del zapato y calcetín de lana.

\section{INDIVIDUO 9}

Individuo masculino adulto joven-maduro, de 30 a 40 años. Marcas de carroñeo en el vértice inferior de la escá-

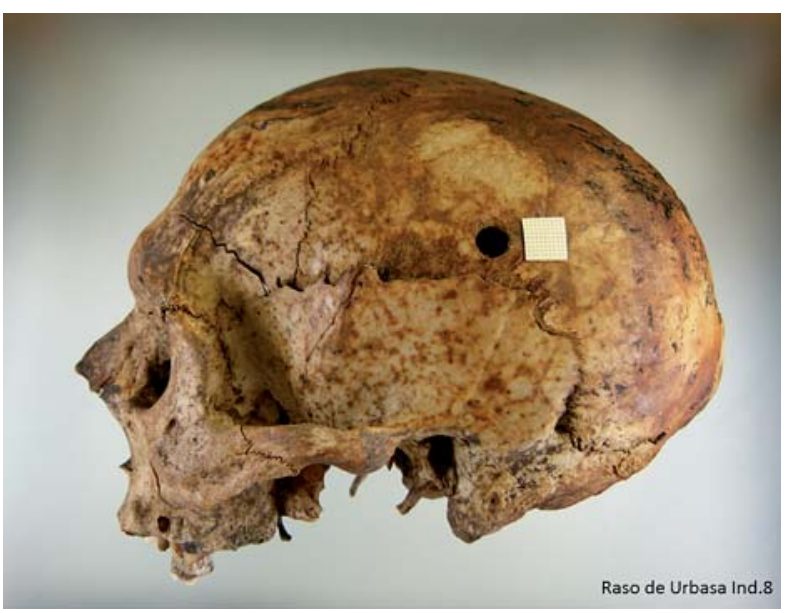

Fig. 23. Orificio de entrada nítido de $7 \mathrm{~mm}$ diámetro en el parietal izquierdo. / A clear $7 \mathrm{~mm}$-diameter entrance hole in the left parietal bone.

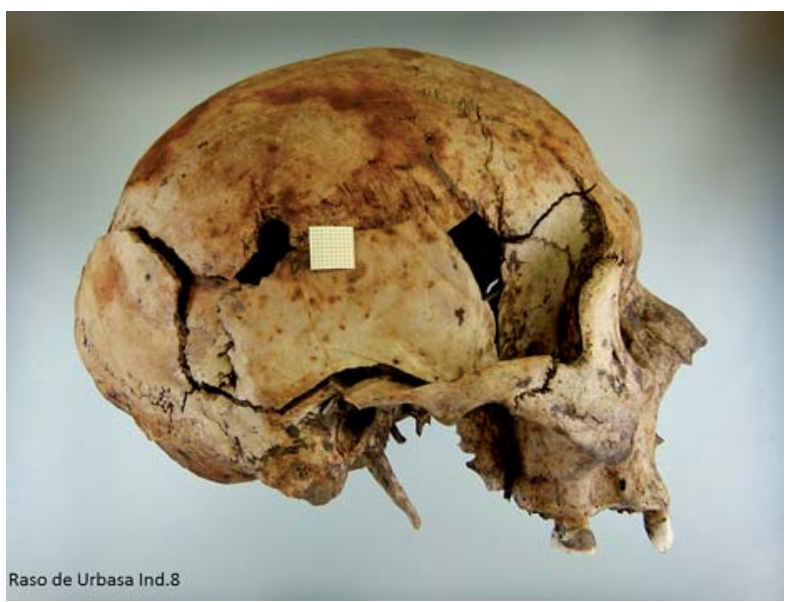

Fig. 24. Orificio de salida con bisel exterior. / Exit hole with external bezel. pula izquierda y extremo acromial de la clavícula del mismo lado. Como variantes anatómicas cabe mencionar la espondilólisis bilateral de L5. Asimismo la primera vértebra sacra muestra dehiscencia del arco. Existen signos degenerativos en la columna con impronta de nódulo de Schmörl en la cara inferior de L5.

Se observan varias fracturas producidas en vida que quedaron bien consolidadas: Callo de fractura en la sexta costilla izquierda. Fractura del arco zigomático y malar del lado izquierdo que se visualiza en una línea que recorre desde el borde lateral externo de la órbita, donde el hueso está ensanchado con una línea de fisura (Figura 25). Erosión craneal por defecto óseo en la mitad izquierda del frontal, en la proximidad de la sien de ese lado. Fractura de los huesos propios de la nariz, caracterizado por la fusión de los huesos nasales. Todas estas fracturas pueden corresponder a un politraumatismo por caída o impacto contra el suelo del costado izquierdo del cuerpo y por golpe directo dado contra el lado izquierdo de la cara.

La causa de muerte se debe al paso de un proyectil en el ángulo interno del techo de la órbita derecha como orificio de entrada. El proyectil atravesó la cavidad craneal para salir rompiendo la apófisis mastoides derecha, donde el orificio presenta una coloración verde por el óxido de cobre del blindaje. En la trayectoria la bala atravesó la base de cráneo que dejó marcas de arrancamiento a su paso.

Objetos asociados: dos botones de nácar de $10 \mathrm{~mm}$ de diámetro, botón metálico de $18 \mathrm{~mm}$ de diámetro y fragmento de tejido de jersey.

\section{INDIVIDUO 10}

Individuo adulto joven, de edad estimada entre los 20 y 25 años. Hay marcas de carroñeo en los vértices inferiores de ambas escápulas, así como en los coxales y en la clavícula izquierda.

Como causa de muerte, en el cráneo existe una pérdida de hueso importante en la región parieto-frontal iz-

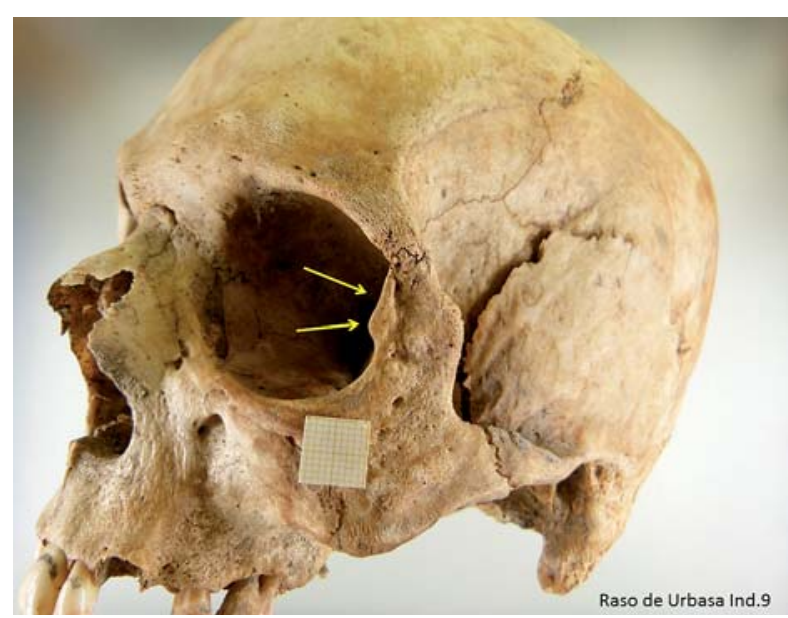

Fig. 25. Fractura consolidada del malar en el borde orbital. / Consolidated fracture on the orbital rim of the malar bone. 


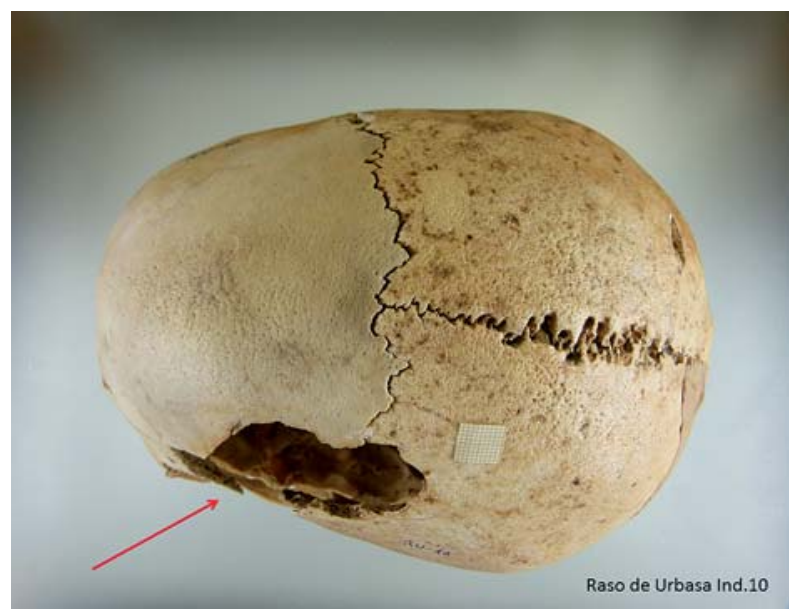

Fig. 26. Entrada de proyectil de arma de fuego. / Bullet entrance.

quierda, donde, además, se observa una fractura concéntrica de $25 \mathrm{~mm}$ con bisel interno (Figura 26). Se interpreta que el proyectil entró por la zona de la sien izquierda produciendo una importante rotura craneal con trayectoria de delante atrás y de izquierda a derecha. Asimismo, en el borde de la zona media del esternón se advierte un recorte en escotadura como consecuencia de un proyectil de arma de fuego que atravesó el esternón y el tórax de delante atrás, izquierda a derecha y de trayectoria descendente (Figura 27).

\subsection{Marcas de carroñeo en los restos humanos recuperados}

Tal y como se ha señalado, todos los restos representados en la muestra de los diez individuos muestran signos de carroñeo. Esta circunstancia caracteriza el estado de conservación de los huesos y limita algunas de las interpretaciones.

En concreto se determinan los signos de la acción de los dientes sobre el hueso que, en este caso, lo habrían producido uno o varios cánidos, cuyos esqueletos se en-

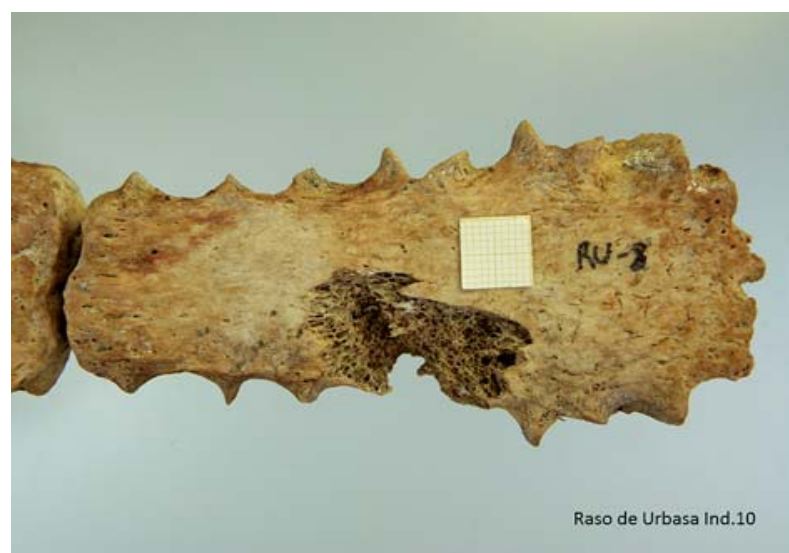

Fig. 27. Cara posterior de esternón con pérdida ósea por paso de proyectil. / Back of the sternum with bone loss caused by bullet passing through. contraban en conexión anatómica junto a los restos humanos en el fondo de la sima. Estos signos son: surcos, rayaduras, punciones y oquedades (HANGLUND et al., 1988 y 1989). De hecho, las epífisis de los huesos largos, caracterizadas por tener mayor cantidad de tejido esponjoso, han desaparecido en su mayor parte, siendo igualmente importante la falta del tejido en los coxales.

Si bien resulta complejo justificar la presencia de los perros en el interior de la sima, lo cierto es que estos actuaron sobre los cadáveres provocando una cierta dispersión de los restos y la desaparición de una parte relevante de su estructura ósea, y de las epífisis de los huesos largos, lo que ha imposibilitado estimar la estatura de los individuos. Estos perros cayeron o fueron introducidos vivos en la sima en la época en la que fueron arrojados los cadáveres humanos a la cavidad. Los perros sobrevivieron por consumo de las partes blandas y practicando el carroñeo de los huesos durante un tiempo prolongado.

El carroñeo de los perros comenzó en las zonas más accesibles del cadáver o del esqueleto, por lo que apenas hay restos de manos o pies. Además de la acción sobre los huesos largos, de gran parte de los coxales solo se conserva la zona de la cresta iliaca. Las escápulas están mordisqueadas en su parte distal y de algunas vértebras sus cuerpos más esponjosos fueron consumidos y solo se han recuperado los arcos.

HAGLUND et al. (1988) establecen cuatro tipos característicos de marcas de dientes de carnívoros en hueso, que están presentes en los restos humanos analizados:

1. Punciones (Punctures). Son marcas o perforaciones nítidas producidas por los dientes cuando se clavan en el hueso. Son características las marcas de los colmillos. Como ejemplo de estos podemos mencionar los dos orificios que presenta la epífisis proximal de un húmero, o varios coxales, tanto en la zona iliaca como en la isquiática (Figura 28).

2. Fosas (Pits). Son indentaciones causadas por las cúspides de los dientes cuando el animal muerde sin la suficiente fuerza para perforar la superficie (Figura 29).

3. Estriaciones (Scoring). Se producen cuando los dientes se deslizan sobre el hueso compacto. Las marcas se localizan en las diáfisis de los huesos largos, en forma de arañazos paralelos orientados transversalmente al eje largo del hueso y siguen el contorno del hueso (Figura 30).

4. Surcos (Furrows). Son canales en el hueso producidos por las cúspides de los molares, que se extienden desde los extremos de los huesos largos por la cavidad medular en sentido longitudinal. La mayor parte de los huesos largos presentan este tipo de signo, y por ello solo restan las diáfisis incompletas. Como ejemplo, se muestran las diáfisis de las tibias izquierdas de los diez individuos con diferente grado de conservación (Figura 31) 

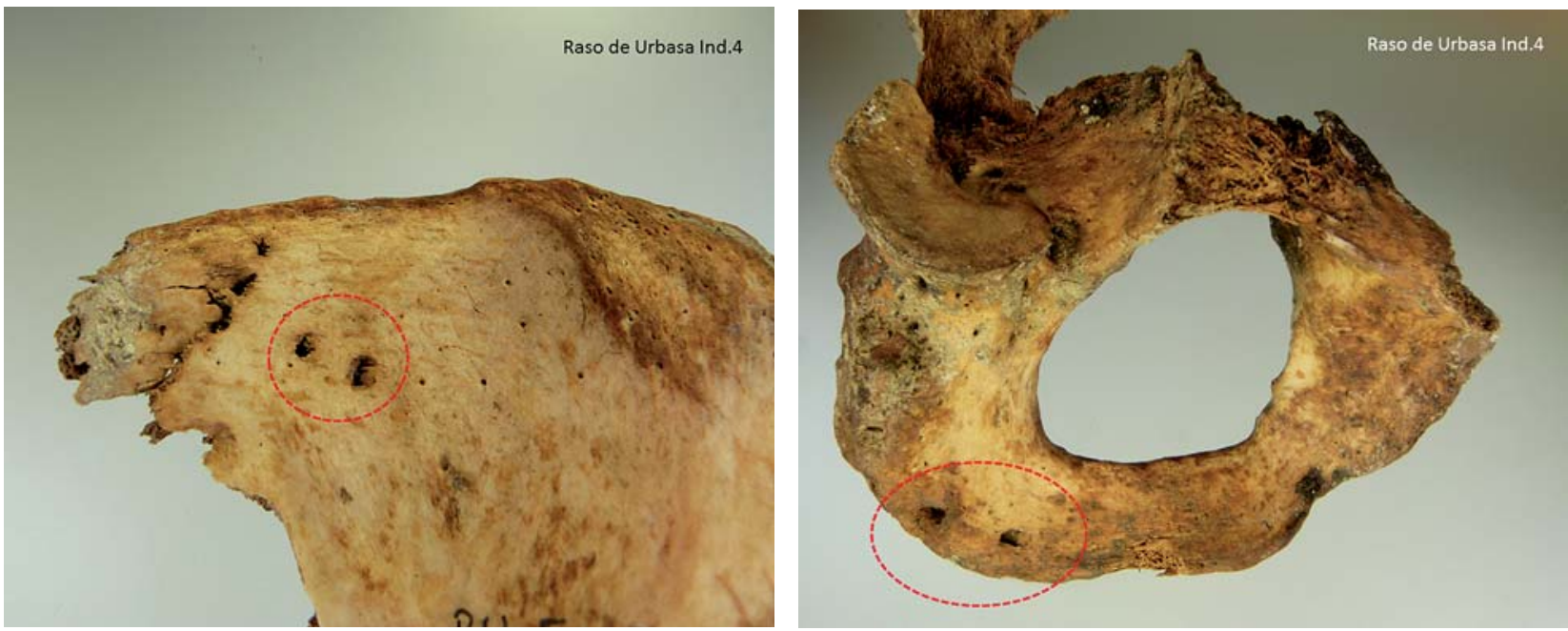

Fig. 28. Ejemplos de punciones en los coxales. / Examples of punctures in the innominate.
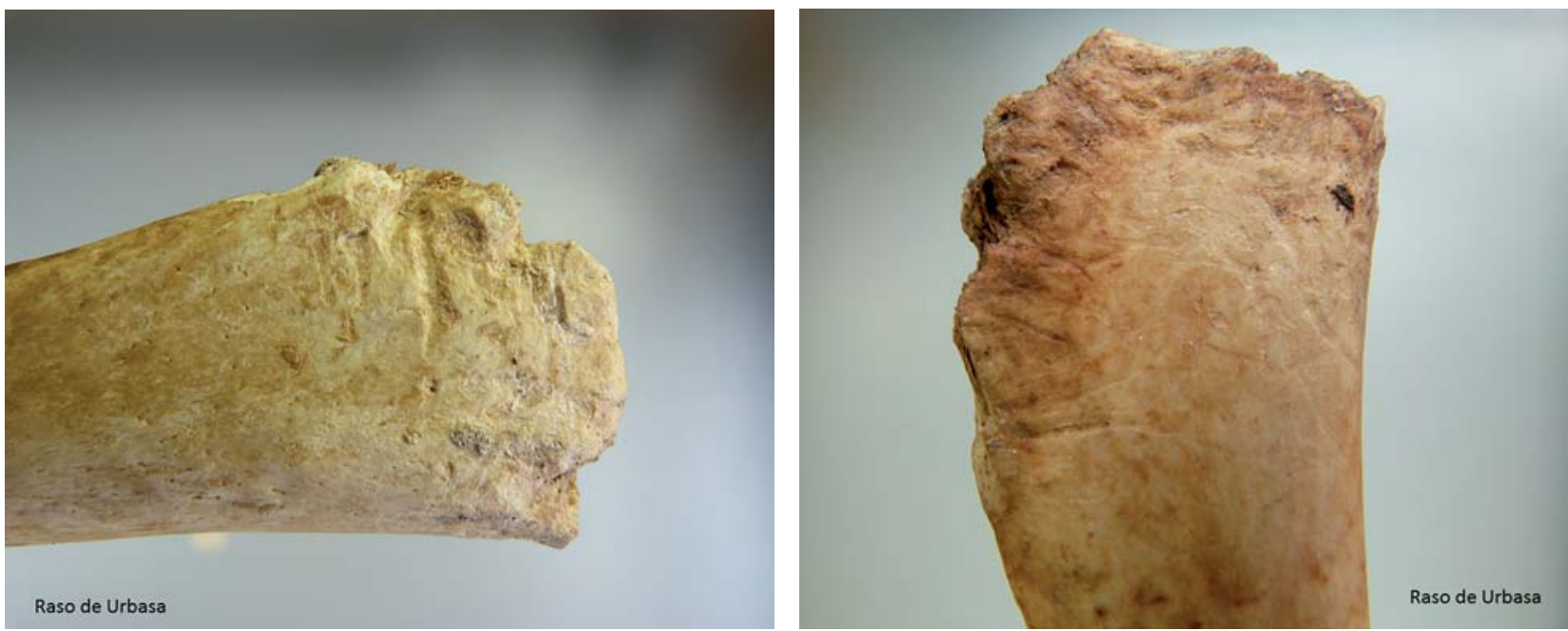

Fig. 29. Fosas o surcos producidos por el rascado de los dientes de los cánidos. / Cavities or grooves due to scraping caused by dogs' teeth.
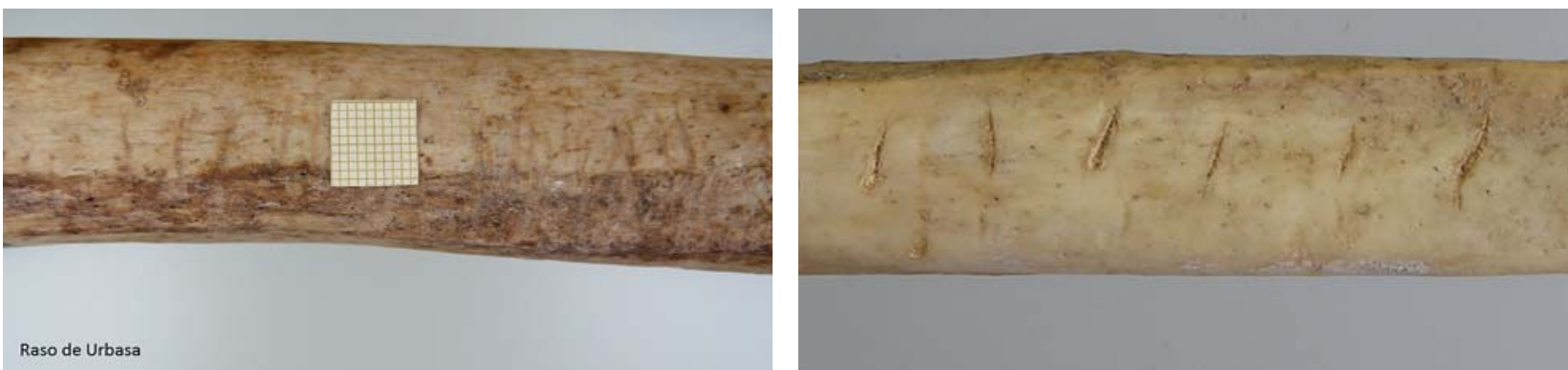

Fig. 30. Estrías paralelas no profundas producidas por arañazos de los dientes. / Shallow parallel striae cause by the scratching of teeth. 


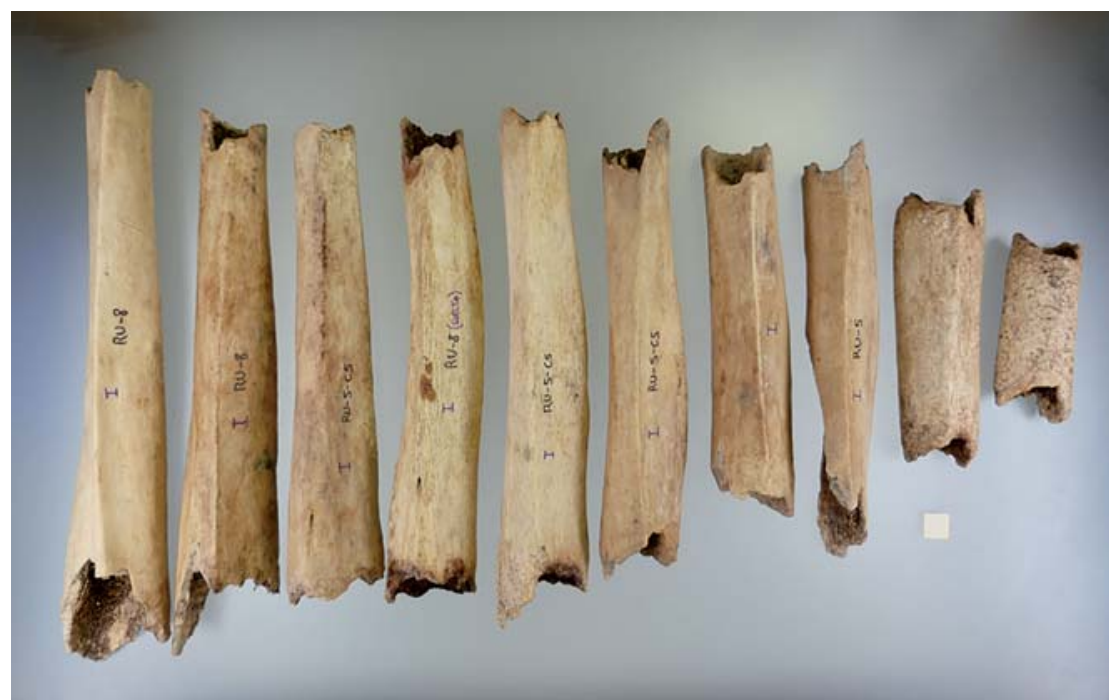

Fig. 31. Diáfisis de las tibias izquierdas de los diez individuos con marcas de surcos en ambos extremos y distintos grados de conservación. / Diaphysis of left tibiae of ten individuals with groove marks at both ends and different degrees of conservation.

\subsection{Causa de muerte}

En lo que respecta a la causa de muerte de las diez personas exhumadas, todas ellas presentan lesiones traumáticas en el cráneo con signos claros de lesión por uno o varios proyectiles de arma de fuego, de los que se han recuperado dos junto a los esqueletos (Figura 32). De lo anterior se deduce que la muerte fue de tipo violenta homicida (Tabla 1). Cabe interpretar, por lo tanto, que estas

\begin{tabular}{|l|l|l|l|}
\hline Referencia & \multicolumn{1}{|c|}{ Sexo } & \multicolumn{1}{|c|}{ Edad } & $\begin{array}{l}\text { Lesión por arma } \\
\text { de fuego }\end{array}$ \\
\hline Individuo 01 & Masculino & Adulto maduro, > 40 años & Cráneo \\
\hline Individuo 02 & Masculino & Adulto joven, 30 años & Cráneo \\
\hline Individuo 03 & Masculino & Adulto joven, > 30 años & Cráneo \\
\hline Individuo 04 & Masculino & Adulto joven, >27 años & Cráneo \\
\hline Individuo 05 & Masculino & Adulto joven, de 27 a 35 años & Cráneo \\
\hline Individuo 06 & Masculino & Adulto maduro-senil, 50 años & Cráneo \\
\hline Individuo 07 & Masculino & Adulto joven, > 30 años & Cráneo \\
\hline Individuo 08 & Masculino & Adulto joven, >27 años & Cráneo \\
\hline Individuo 09 & Masculino & Adulto joven-maduro,>35 años & Cráneo \\
\hline Individuo 10 & Masculino & Adulto joven, >20 años & Cráneo y tórax \\
\hline
\end{tabular}

Tabla 1: Síntesis de la muestra osteológica humana. / Synthesis of the human osteological sample.

(2)
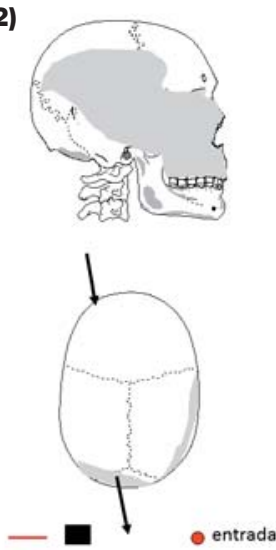
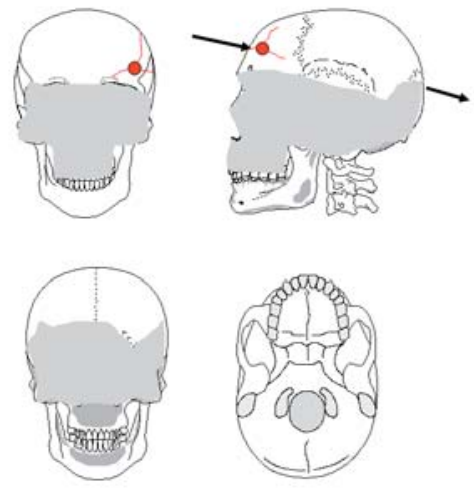

Raso de Urbasa 02 personas fueron asesinadas con uno o varios disparos en el exterior de la cavidad y posteriormente sus cadáveres fueron arrojados a la sima por el pozo vertical de entrada para su ocultamiento.

(1)
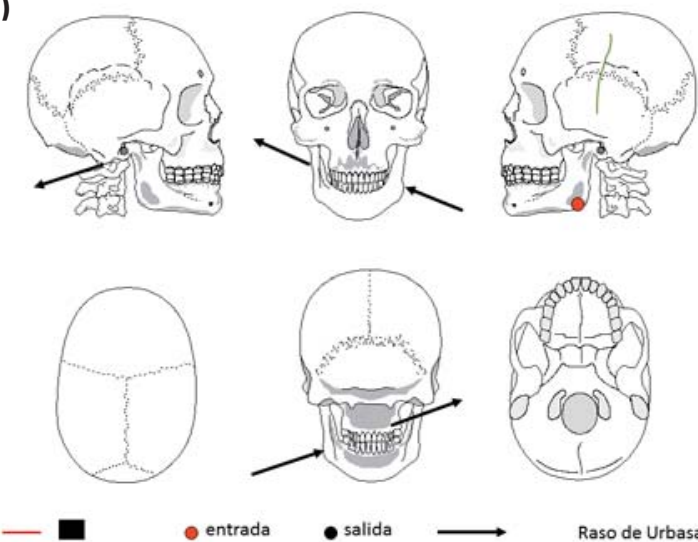

- entrada

- salida

Raso de Urbasa 01

(3)
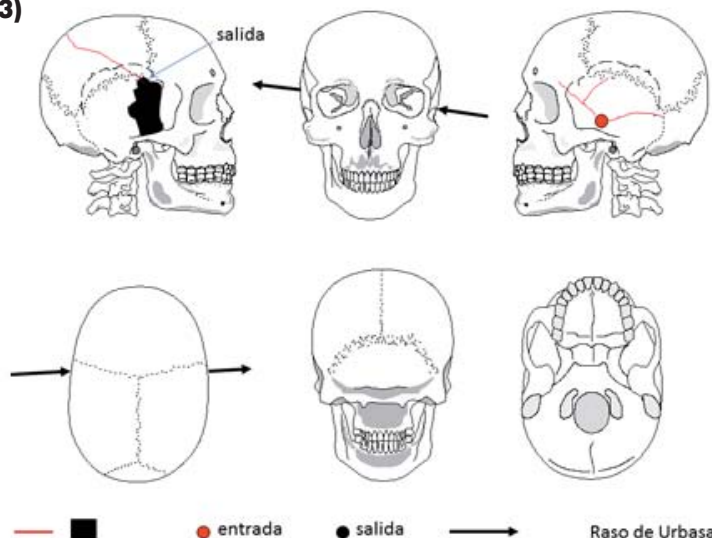

$-$ 
(4)
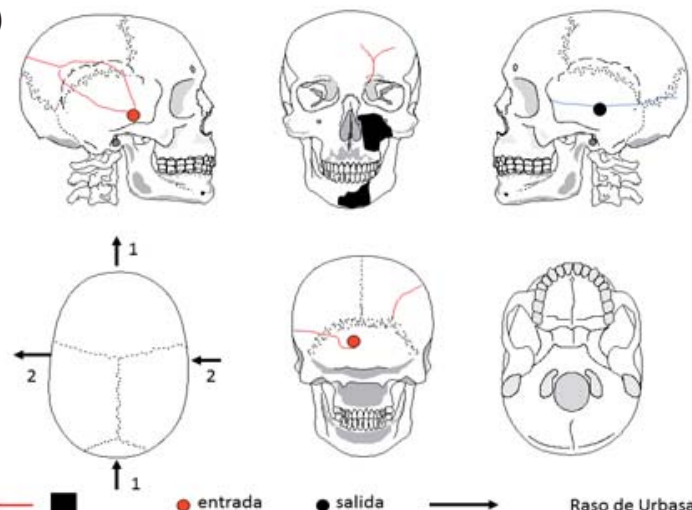

(5)
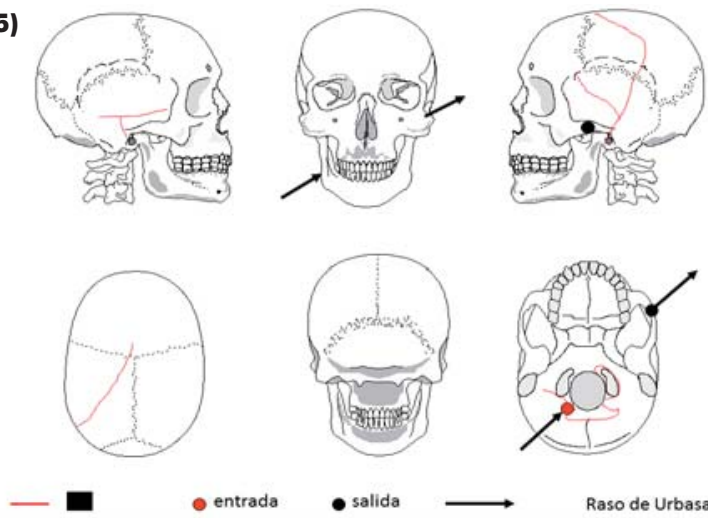

(6)
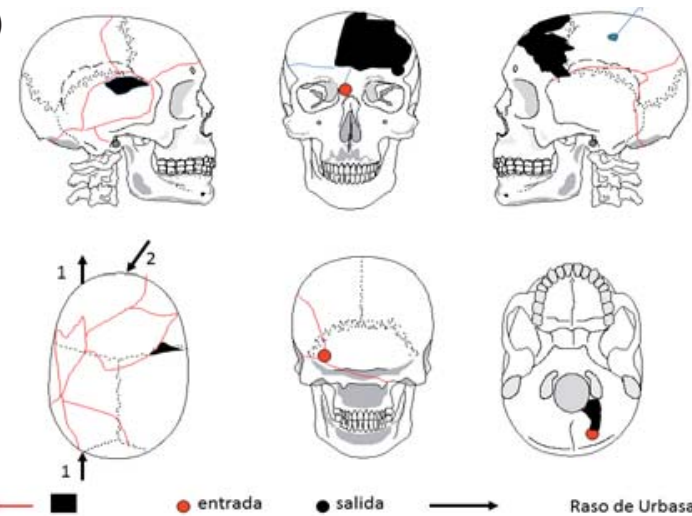

- salida

Raso de Urbasa 06

(7)
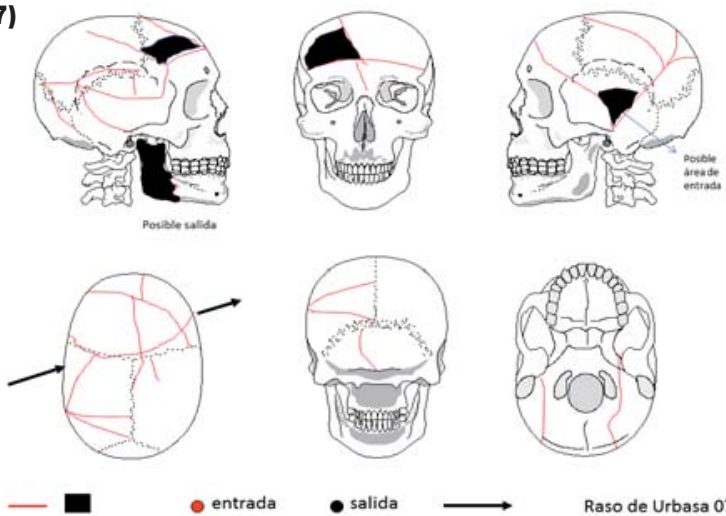

- salida

(8)
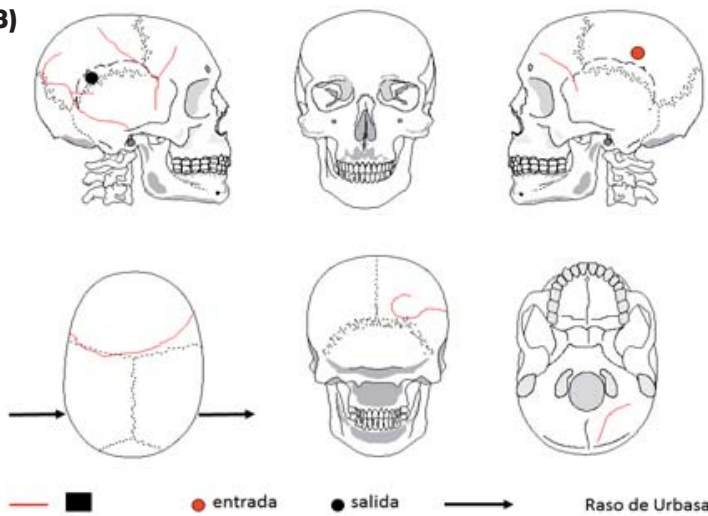

Raso de Urbasa 08

(9)
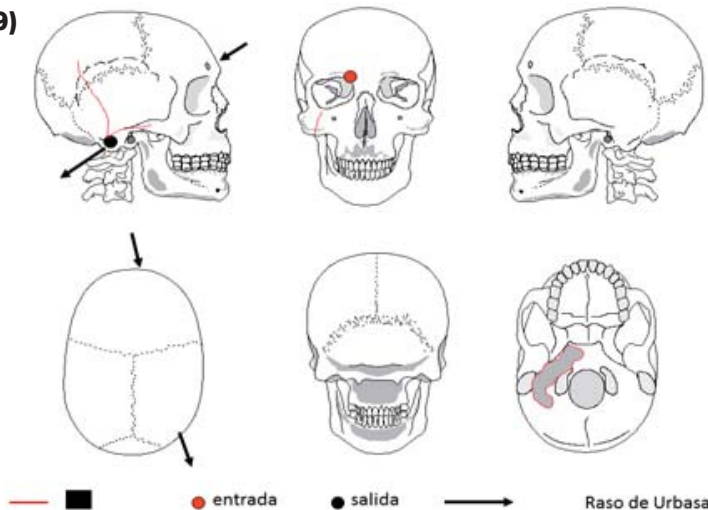

- salida

Raso de Urbasa 09

(10)
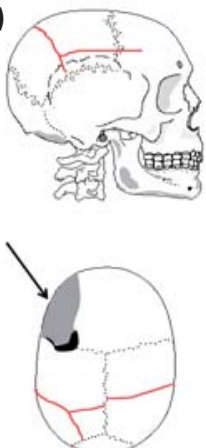

- entrada
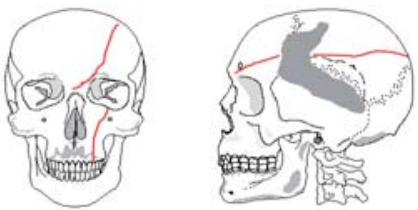

Fig. 32. Representación esquemática de las heridas por arma de fuego Schematic diagram of gunshot wounds.

\section{5.- IDENTIFICACIÓN GENÉTICA}

Tras el análisis de los restos desde la perspectiva antropológica se realizaron dos informes genéticos: BADN764775_809_810_814GC-BIO de fecha 2 de diciembre de 2014 y BADN835-838GC-BIO de fecha 17 de abril de 2015.

\subsection{Metodología del análisis genético}

Se realizó el análisis genético de los restos post-mortem de diez individuos hallados en la Sima de Urbasa, así 
como de muestras de saliva pertenecientes a nueve familiares, con el objetivo de realizar el estudio comparativo para la identificación de los restos. Los análisis se realizaron en los laboratorios del Grupo BIOMICs de la Universidad del País Vasco UPV-EHU.

En el caso de los restos post-mortem, se seleccionó una pieza dental o un fragmento de hueso de cada individuo, y se procedió a su limpieza y pulverización. La limpieza consistió en el raspado de la superficie de cada muestra, seguida de un lavado con lejía (5\%) y agua ( $\mathrm{H} 2 \mathrm{O}$ milliQ estéril) y posterior irradiación con luz ultravioleta (UV), para retirar la suciedad que pudiese inhibir los posteriores procesos de análisis, así como la posible presencia de ADN exógeno que pudiese contaminar la muestra. A continuación, cada muestra fue pulverizada de manera individual en un molino criogénico Freezer Mill 6750 (Spex Sample Prep) refrigerado con nitrógeno líquido, lo que previene la degradación del ADN por el calor desprendido durante el proceso de triturado. La extracción de ADN se realizó mediante un protocolo de cromatografía de afinidad (Qiagen), adaptado al sistema Hi-Flow® DNA Purification Spin Columns (Generon) (modificado de MARSHALL et al. 2014). El ADN extraído fue cuantificado mediante QuantifilerTM Human DNA Quantification (AB/LT/TFS: Applied Biosystems ${ }^{\mathrm{TM}}$, Life Technologies, ThermoFisher Scientific, Waltham, MA, USA).

Todas las muestras de los familiares fueron tomadas previa solicitud de consentimiento informado. El ADN fue extraído mediante un protocolo de Puregene DNA Purification System (Gentra Systems) y cuantificado mediante espectrometría con un NanoDrop 1000 (Thermo Scientific).

Una parte alícuota del ADN extraído fue utilizada para amplificar los marcadores microsatélites o STRs (Short Tandem Repeats) autosómicos y el locus amelogenina, mediante los kits comerciales AmpFlSTR NGM SElect PCR Amplification Kit y/o AmpFlSTR®MiniFilerTM PCR Amplification Kit (AB/LT/TFS) en el caso de las muestras dubitadas, y el múltiplex IDNA-SE21 (AZNAR y col., 2014) en el caso de muestra indubitadas. También se analizaron marcadores STRs del cromosoma Y (Y-STRs) mediante los kits comerciales YFilerTM (AB/LT/TFS) o PowerPlexY23® (Promega). Adicionalmente, en determinados casos de parentesco se estudiaron STRs del cromosoma X (X-STRs) (PRIETO-FERNÁNDEZ y col., 2015). También se analizó la región control de ADN mitocondrial (ADNmt) de determinadas muestras para estudiar las relaciones por vía matrilineal. En el caso de los restos post-mortem se analizaron los segmentos hipervariables HVS-I y HVS-II de la región control del ADNmt. Cada uno de estos segmentos fueron amplificados por PCR mediante seis parejas solapantes de cebadores, tres para cada segmento (HVS-I: L15988H16166, L16159-H16311, L16287-H16406; HVS-II: L12H142, L135-H285, L281-H408.2). En el caso de las muestras indubitadas se analizó toda la región control del ADNmt mediante el procedimiento descrito por CARDOSO y col., (2012) Todos los productos amplificados fueron analizados mediante electroforesis capilar en un analizador automático de ADN ABI 3130 (AB/LT/TFS).
Finalmente, los perfiles genéticos de los restos postmortem fueron contrastados con los obtenidos de muestras de los familiares para poder establecer así posibles relaciones de parentesco. En todos los casos de compatibilidad, se realizó la pertinente valoración de la probabilidad de parentesco mediante el sistema de cálculo Genética Forense de A. Vozmediano (http://antonio.scienceontheweb.net/gff.htm).

\subsection{Resultados del análisis genético}

Una vez estudiados los restos post-mortem de los 10 individuos hallados en la Sima de Urbasa, la cuantificación de ADN fue exitosa en el $60 \%$ de los casos, teniendo en cuenta el límite de detección de Quantifiler (0,023 $\mathrm{ng} / \mathrm{\mu l})$. El resto de muestras generaron valores positivos de cuantificación por debajo del límite de detección.

El estudio genético de los restos post-mortem de la fosa de la Sima de Urbasa ha permitido la obtención de perfiles genéticos informativos ( $\geq 12$ STRs) (PRINZ y col., 2007) en el $80 \%$ de los restos analizados tanto para STRs autosómicos como Y-STRs. El análisis de 17 X-STRs en un resto post-mortem proporcionó un perfil genético completo. Asimismo, el análisis de ADNmt en tres restos postmortem permitió obtener las regiones HVS-I y HVS-II en la totalidad de las muestras analizadas.

En total se identificaron ocho restos que ofrecieron compatibilidad con las muestras de referencia disponibles (Tabla 2).

\begin{tabular}{|l|l|c|l|}
\hline & $\begin{array}{l}\text { Relación de parentesco } \\
\text { investigada }\end{array}$ & $\begin{array}{l}\text { Restos post-mortem con } \\
\text { compatibilidad genética }\end{array}$ & $\begin{array}{l}\text { Marcadores genéticos analizados } \\
\text { que muestran compatibilidad }\end{array}$ \\
\hline 1 & Tío materno - Sobrino & Individuo 1 & ADN mitocondrial \\
\hline 2 & Abuelo - Nieto Paterno & Individuo 2 & $\begin{array}{l}\text { STRs autosómicos / } \\
\text { STRs del cromosoma Y }\end{array}$ \\
\hline 3 & Abuelo - Nieto Paterno & Individuo 3 & STRs del cromosoma Y \\
\hline 4 & Padre - Hija & Individuo 4 & STRs autosómicos \\
\hline 5 & Padre - Hija & Individuo 5 & $\begin{array}{l}\text { STRs autosómicos / } \\
\text { STRs del cromosoma X }\end{array}$ \\
\hline 6 & Abuelo - Nieto Paterno & Individuo 6 & STRs del cromosoma Y \\
\hline 7 & Abuelo - Nieto Paterno & Individuo 8 & $\begin{array}{l}\text { STRs autosómicos / } \\
\text { STRs del cromosoma Y }\end{array}$ \\
\hline 8 & Abuelo - Nieto Paterno & Individuo 10 & STRs autosómicos \\
\hline
\end{tabular}

Tabla 2: Relación de restos post-mortem que ofrecieron compatibilidad con las distintas muestras de referencia. Se indica la relación de parentesco investigada el resto post-mortem con compatibilidad genética y los marcadores genéticos analizados que muestran compatibilidad. / List of the post-mortem remains that provided compatibility with the different reference samples. It includes the blood relation investigated, the post-mortem remains with genetic compatibility, and the genetic markers analysed and which display compatibility.

En los casos de las relaciones padre-hija, el análisis de los STRs autosómicos fue imprescindible para establecer las identificaciones. Adicionalmente, en uno de estos casos el uso de STRs del cromosoma X sirvió para incrementar el valor probabilístico de la relación de parentesco en combinación con los STRs autosómicos. En cuanto a las relaciones abuelo-nieto paterno, el análisis de STRs del cromosoma Y permitió establecer las relaciones de parentesco por vía patrilineal y, en algunos casos, los STRs autosómicos proporcionaron unos valores de probabilidad 
suficientes como para incrementar la confianza en la identificación. Finalmente, el análisis del ADN mitocondrial fue decisivo para establecer una relación de parentesco por vía matrilineal (tío materno-sobrino).

\section{6.- IDENTIDAD DE LAS VÍCTIMAS}

Teniendo en cuenta la información histórica de los hechos y una vez establecida la identificación de los restos, sabemos que las muertes se produjeron en tres fechas distintas: el 8 de agosto, y el 6 y 7 de septiembre de 1936 (Tabla 3 y Figura 33).

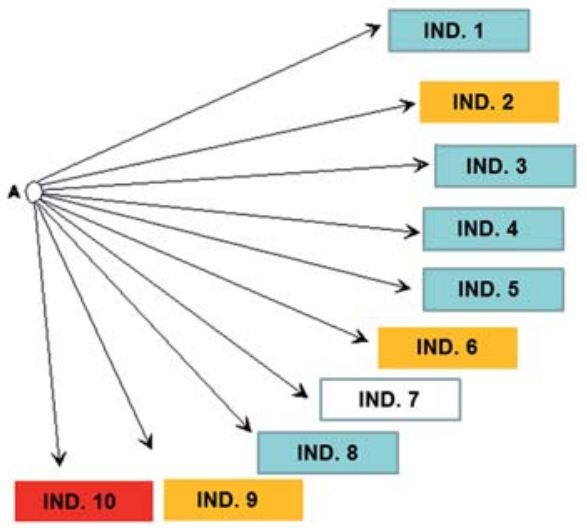

08-08-36

06-09-36 07-09-36

Fig. 33. Distribución espacial en función de la fecha de asesinato. / Spatial distribution according to date of murder.

\section{- Asesinato del 8 de agosto de 1936.}

- José Urbizu Besarategui, natural de Zegama (Gipuzkoa), tenía 20 años. Se había trasladado a Olazti para preguntar por el paradero de su padre, Martín Urbizu Otaño, que había desaparecido la víspera. Fue detenido y obligado a introducirse en un coche, en el que fue trasladado a la sierra de Urbasa. Se negó a bajar del coche y tras un forcejeo le dispararon en el tórax y en la cabeza, cuando todavía estaba dentro del automóvil5.

- Grupo del 6 de septiembre: ese día fueron ejecutados y arrojados a la sima cinco vecinos de Etxarri Aranaz, que compartían su pertenencia a la Junta Local de UGT del municipio.

- Paulo Garciandía Arín, de 43 años, trabajaba en Bilbao, pero se encontraba de vacaciones en Etxarri cuando fue detenido con el resto del grupo.

- Andrés González Lorente, nacido en Calahorra (La Rioja) y vecino de Bilbao. De oficio guardagujas.

- Clemente Araña Miguel de Echarri de 29 años, era natural de Etxarri Aranaz. Estaba casado y era padre de cuatro hijos.

- Narciso Artola Razquín era agricultor y padre de cuatro hijos.

- Antonio Maiza Miranda, de 29 años de edad. Estaba casado y trabajaba en una serrería.

- Grupo asesinado el 7 de septiembre de 1936: formado por tres vecinos de Eulate y San Martín de Améscoa. También estaban afiliados a UGT.

- Balbino Bados García, de 29 años de edad, era maestro en Peralta. Había nacido en San Martín de Améscoa.

- Balbino García de Albizu Usarbarrena era de Eulate. Trabajaba de guarda forestal en el monte Limitaciones (Urbasa). Casado y padre de siete hijos.

- Gregorio García Larrambebere, de 49 años y vecino de Eulate. Era viudo y no tuvo hijos. Además de su filiación en el sindicato socialista, colaboraba en el seminario "Trabajadores".

\begin{tabular}{|c|l|c|l|c|}
\hline $\begin{array}{c}N^{\circ} \\
\text { Ind. }\end{array}$ & \multicolumn{1}{|c|}{ Identidad } & Edad & \multicolumn{1}{c|}{ Profesión } & $\begin{array}{c}\text { Día } \\
\text { desaparición }\end{array}$ \\
\hline 1 & Paulo Garciandia Arín & 43 & Obrero fábrica & $06-09-1936$ \\
\hline 2 & Balbino Bados García & 29 & Maestro & $07-09-1936$ \\
\hline 3 & Andrés González Lorente & 32 & Guardagujas & $06-09-1936$ \\
\hline 4 & Clemente Araña Miguel de Echarri & 29 & Empleado & $06-09-1936$ \\
\hline 5 & Narciso Artola Razquín & 32 & Agricultor & $06-09-1936$ \\
\hline 6 & Balbino García de Albizu Usarbarrena & 59 & Guarda forestal & $07-09-1936$ \\
\hline 7 & (masculino >30 años) & & & $06-09-1936$ \\
\hline 8 & Antonio Maiza Miranda & 29 & Obrero serrería & $07-09-1936$ \\
\hline 9 & Gregorio García Larrambebere & 49 & Colaborador de "Trabajadores" & $08-08-1936$ \\
\hline 10 & José Urbizu Berasategui & 20 & Trabajador forestal & \\
\hline
\end{tabular}

Tabla 3: Identidades de las víctimas. / Identity of the victims

\footnotetext{
${ }^{5}$ Aurori Urbizu, nieta de Martín Urbizu y sobrina de José Urbizu, relató, en testimonio grabado por la Sociedad de Ciencias Aranzadi en octubre de 2003, cómo su tío José, sabedor de lo que le iba a ocurrir, se negó a bajar del coche cuando se lo requirieron: "que te bajes". "No". "... tiroa auto barruan eman zioten eta ondoren kotxea garbitu behar izan zuten". Ante la negativa y, quizás después de un forcejeo, le dispararon dos tiros hechos a corta distancia en el tórax y la cabeza, cuando todavía se encontraba en el coche. En el libro autobiográfico escrito por Pedro Salinas Arregui narra cómo fue detenido el 9 de agosto de 1936, conducido preso a Vitoria y trasladado, junto con los maestros de Zalduendo, Galarreta y Gordoa, para ser fusilado en la sierra de Urbasa. "Llegamos a Urbasa, forcejeo y golpes ya que no queremos salir de los coches negros, uno me apunta con su fusil y otro le aconseja: "no le tires, que salga, que no va llenar el coche de sangre, acuérdate de lo que pasó ayer". Se referiría al asesinato de José Urbizu dentro del coche, que tuvo lugar el día anterior, 8 de agosto de 1936. Pedro Salinas consiguió escapar y sobrevivió.
} 
No se conoce, por el momento, la identidad de la décima persona que se correspondería con el individuo número 7. Podría tratarse, quizás, de un trabajador de la fábrica de Olazti o del ferrocarril.

\section{7.- RESTOS FAUNÍSTICOS ASOCIADOS A LOS RESTOS HUMANOS}

Tal y como se ha señalado, junto a los restos humanos se encontraron otros de tipo faunístico en el interior de la sima. Por tal motivo se ha realizado la estimación del número mínimo de individuos de cada especie de mamíferos presente y su posible relación con los restos humanos afectados por carroñeo. En el caso de los perros se incluye un estudio osteométrico con las medidas básicas del cráneo y huesos largos. Se ofrece también el índice de robustez de las extremidades y la altura en la cruz de cada individuo. Se intenta una cierta "aproximación" de cada individuo a tipologías raciales actuales y la secuencia de pervivencia de cada ejemplar respecto de sus congéneres.

\subsection{Metodología del análisis osteoarqueológico}

Todas las medidas se han tomado en mm con un margen de error de 0,1 $\mathrm{mm}$. Se ha utilizado la metodología de A.v.d. DRIESCH (1976). El índice cefálico total (ICT) es la relación porcentual entre la anchura máxima del cráneo (medida como máxima distancia entre los arcos cigomáticos) y su longitud máxima medida entre la protuberancia occipital externa (Akrokranion) y el extremo rostral de la incisura interincisiva (Prosthion). La estimación de la altura en la cruz (AC) se ha realizado a partir de la longitud de los huesos largos de las extremidades aplicando los factores de HARCOURT (1974). El índice de robustez de los huesos largos es la relación porcentual entre la anchura mínima de la diáfisis (AD) y la longitud máxima del hueso (LM).

\subsection{Metodología del análisis osteoarqueológico}

Se han identificado restos de seis perros (Canis familiaris), dos cerdos (Sus domesticus), dos ovejas (Ovis aries) y un équido que puede ser caballo o asno (Equus caballus/Equus asinus). El grado de conservación del esqueleto en cada individuo es muy variado, oscilando entre un sólo resto (un perro y una oveja), dos en el caso de otra oveja, entre 12 y 19 restos en los dos cerdos, una oveja y el équido y casi todo el esqueleto en los demás perros.

Respecto de la distribución original se han reagrupado los restos en bolsas según la especie y el individuo quedando algunos restos sin asignación a ningún individuo pero pertenecientes a alguno de los descritos.

Se han separado en una bolsa unos pocos restos humanos y en otra una herradura.

\subsection{Perros}

Hay restos de cinco individuos distintos, cuatro con el esqueleto casi completo y uno sólo con el cráneo de los que se ofrecen los datos más relevantes de cada individuo.

\section{Perro $\mathrm{n}^{\circ} 1$}

Se trata de un individuo adulto, probablemente hembra a juzgar por el escaso desarrollo de la cresta occipital y la ausencia de báculo o hueso penneano. Conserva el cráneo completo con las dos series dentarias superiores y las dos mandíbulas inferiores (Figura 34). Faltan algunas piezas dentarias. Los huesos largos de las extremidades están completos salvo medio peroné. Se conservan la mayor parte de la columna vertebral, costillas, carpales, tarsales, metapodios y falanges. No presenta evidencia alguna de mordeduras en sus huesos.

La dentadura presenta una oclusión normal entre las series superior e inferior. Por otro lado los ejes longitudinales craneal y del hocico forman un ángulo divergente.

Medidas craneales: Longitud máxima (AkrokranionProsthion): 177,2. Anchura máxima: 96,4. Índice cefálico total (ICT): 54,4. Se trata de un individuo mesocéfalo cercano al límite con los braquicéfalos (más de 55).

La robustez de los huesos largos oscila entre los índices 6,45 en la tibia y 7,8 en el radio con un valor medio de 7,41 calculando el promedio de los cuatro huesos. Estos datos indican que se trata de un ejemplar bastante grácil. Su altura en la cruz oscila entre 486,58 y 500,11 con un valor medio de 493, 01 considerando los cuatro huesos. Esta alzada a modo de comparación queda incluida dentro de la mitad inferior del dominio de variación de hembras (460-590) de perro pastor vasco tanto en su variedad lanas como en la variedad del Gorbea (GÓMEZ, 1994).

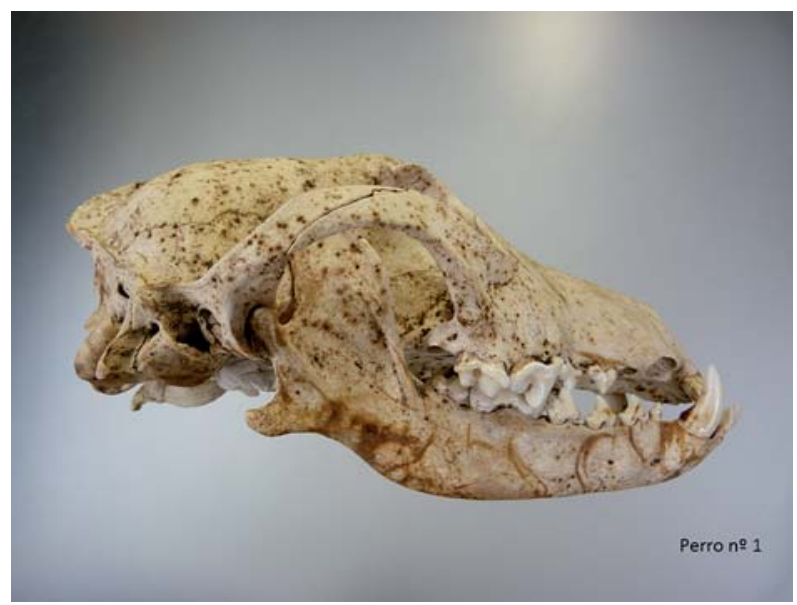

Fig. 34. Cráneo del perro número 1 (norma lateral derecha). / Skull of dog number 1 (right norma lateralis).

\begin{tabular}{|l|c|c|c|c|}
\hline & HÚMERO & RADIO & FÉMUR & TIBIA \\
\hline LM & 149,6 & 148,7 & 163,4 & 167,4 \\
\hline AM & 10,5 & 11,6 & 11,7 & 10,8 \\
\hline IR & 7,14 & $\mathbf{7 , 8}$ & 7,16 & $\mathbf{6 , 4 5}$ \\
\hline AC & $\mathbf{4 8 6 , 5 8}$ & 492,36 & $\mathbf{5 0 0 , 1 1}$ & 498,21 \\
\hline
\end{tabular}

Tabla 4: Índice de robustez (IR) y altura en la cruz (AC). / Robustness index (RI) and crossover height $(\mathrm{CH})$. 


\section{Perro $n^{\circ} 2$}

Se trata de un individuo adulto más pequeño que el anterior y también hembra a juzgar por el escaso desarrollo de la cresta occipital y la ausencia de báculo o hueso penneano. Conserva el cráneo completo con las dos series dentarias superiores y las dos mandíbulas inferiores (Figura 35). Faltan algunas piezas dentarias. Los huesos largos de las extremidades están completos salvo los dos peronés. Se conservan la mayor parte de la columna vertebral, costillas, carpales, tarsales, metapodios y falanges. No presenta evidencia alguna de mordeduras en sus huesos.

La oclusión entre las series dentarias superior e inferior es normal. Entre el eje longitudinal craneal y el eje longitudinal del hocico el ángulo es también divergente.

Medidas craneales: Longitud máxima (AkrokranionProsthion): 154,5. Anchura máxima: 86 . Índice cefálico total (ICT): 55,66. Se trata de un individuo ligeramente braquicéfalo en el mismo límite con los mesocéfalos (46-55).

\begin{tabular}{|l|c|c|c|c|}
\hline & HÚMERO & RADIO & FÉMUR & TIBIA \\
\hline LM & 134,7 & 132,4 & 142,2 & 146,8 \\
\hline AM & 11 & 10,2 & 11 & 10,8 \\
\hline IR & $\mathbf{8 , 1 6}$ & 7,7 & 7,73 & $\mathbf{7 , 3 5}$ \\
\hline AC & 435,48 & $\mathbf{4 4 0 , 5 4}$ & $\mathbf{4 3 2 , 5 4}$ & 438,06 \\
\hline
\end{tabular}

Tabla 5: Índice de robustez (IR) y altura en la cruz (AC). / Robustness index $(\mathrm{RI})$ and crossover height $(\mathrm{CH})$.

El índice de robustez de los huesos largos oscila entre 7,35 para la tibia y 8,16 para el húmero. Considerando los cuatro huesos se obtiene un valor medio de 7,73 que es algo mayor que el del perro $n^{\circ} 1$. La altura en la cruz oscila entre 432,54 y 440,54 con un valor medio de 436,66 considerando los cuatro huesos. Esta alzada es menor que la del ejemplar anterior y también queda incluida dentro de la mitad inferior del dominio de variación de hembras (460590) de perro pastor vasco tanto en su variedad lanas como en la variedad del Gorbea (GÓMEZ, 1994).

\section{Perro $n^{\circ} 3$}

Se trata de un individuo con características similares a los dos anteriores

Conserva la mayor parte del esqueleto. Entre los huesos largos falta un peroné. El escaso desarrollo de la cresta occipital indica que se trata de una hembra.

En el húmero izquierdo le falta la articulación proximal que ha sido comida por otro perro ya que conserva huellas claras de mordidas en el extremo de la diáfisis rota. Lo mismo ocurre con el extremo proximal de la tibia derecha por la misma causa. Además el fémur izquierdo presenta huellas de mordeduras tanto en la articulación proximal como distal que no han llegado a fracturar el hueso.

La oclusión entre las series dentarias superior e inferior es normal. Entre el eje longitudinal craneal y el eje longitudinal del hocico el ángulo es también divergente.

Medidas craneales: Longitud máxima (AkrokranionProsthion): 173,2. Anchura máxima: 96,5. Índice cefálico

\begin{tabular}{|l|c|c|c|c|}
\hline & HÚMERO & RADIO & FÉMUR & TIBIA \\
\hline LM & 150 & 144,6 & 159 & 159,5 \\
\hline AM & 12,4 & 12,1 & 12,4 & 11,6 \\
\hline IR & 8,26 & $\mathbf{8 , 3 6}$ & 7,79 & $\mathbf{7 , 2 7}$ \\
\hline AC & $\mathbf{4 8 7 , 9 6}$ & 479,33 & 486,3 & $\mathbf{4 7 5 , 1 5}$ \\
\hline
\end{tabular}

Tabla 6: Índice de robustez (IR) y altura en la cruz (AC). / Robustness index (RI) and crossover height (CH).

total (ICT): 55,7. Presenta un índice cefálico similar al del ejemplar anterior. Por tanto se trata de un individuo ligeramente braquicéfalo en el mismo límite con los mesocéfalos (46-55).

El índice de robustez de los huesos largos oscila entre 7,27 para la tibia y 8,26 para el radio. Considerando los cuatro huesos se obtiene un valor medio de 7,92 que supera al de los dos anteriores. La altura en la cruz oscila entre 475,15 y 487,96 con un valor medio de 482,18 considerando los cuatro huesos. Esta alzada es intermedia entre los perros $n^{\circ} 1$ y n². También queda incluida dentro de la mitad inferior del dominio de variación de hembras (460-590) de perro pastor vasco tanto en su variedad lanas como en la variedad del Gorbea (GÓMEZ, 1994).

\section{Perro $n^{\circ} 4$}

Este individuo sólo conserva el cráneo (sin mandíbulas). Por tanto sólo se puede disponer de información cefálica. Presenta un mayor desarrollo de la cresta sagital por lo que pudiera corresponder a un macho.

Medidas craneales: Longitud máxima (AkrokranionProsthion): 187. Anchura máxima: 106. Índice cefálico total (ICT): 56,68. Es el más braquicéfalo de los cuatro descritos aunque no esté muy alejado del límite con los mesocéfalos.

\section{Perro $n^{\circ} 5$}

Se trata de un ejemplar que difiere de los demás tanto por su edad como por su robustez. En la dentadura superior sólo ha emergido el primer molar definitivo mientras que el resto de las piezas (incluido el canino) apenas inician la erupción. Lo mismo ocurre en la dentadura inferior con un ligero adelanto del proceso de erupción en los últimos premolares respecto del resto. Con estos datos se puede estimar su edad oscila entre cuatro y cinco meses. Todos los huesos largos tienen sin fusionar tanto las epífisis proximales como las distales.

Medidas craneales: Longitud máxima (AkrokranionProsthion): 175,5. Anchura máxima: 86,5. Índice cefálico total (ICT): 49,28. Presenta un índice cefálico más pequeño que el resto de los perros. Se trata de un individuo claramente mesocéfalo. Estos datos han de tomarse con cierta reserva ya que se trata de un ejemplar inmaduro que puede tener sin completar el desarrollo cefálico.

\begin{tabular}{|l|c|c|}
\hline & RADIO & TIBIA \\
\hline LM & 131,2 & 149 \\
\hline AM & 11,9 & 12,2 \\
\hline IR & 9,07 & 8,18 \\
\hline AC & 436,72 & 444,49 \\
\hline
\end{tabular}

Tabla 7: Índice de robustez (IR) y altura en la cruz (AC). Robustness index (RI) and crossover height $(\mathrm{CH})$. 
Se trata del perro con mayor robustez de la muestra (8,62 de media). Sin embargo, teniendo en cuenta que la longitud del hueso largo no es aún definitiva, este dato debe tomarse con reservas. La altura en la cruz está afectada por el mismo problema ya que se estima a partir de la longitud definitiva de los huesos largos y en este caso las dimensiones del radio y de la tibia no son definitivas. El animal al terminar su proceso de crecimiento hubiese tenido más de 440,6 mm de alzada.

Los huesos no presentan mordeduras claras. Se aprecia una pequeña erosión en el olécranon de la ulna derecha pero no parece producida por un mordisco.

\section{Pervivencia de los distintos perros}

Los perros son los únicos agentes potenciales del consumo parcial de los cadáveres humanos si se tiene en cuenta que el resto de las especies presentes son herbívoros. Por esta razón parece interesante determinar la secuencia de supervivencia de los perros.

El individuo más joven puede que no tuviera relación alguna con los restos humanos y su presencia en la cavidad no fuese sincrónica con ellos. Un cachorro hubiese sido una víctima fácil en momentos de necesidad extrema. Sin embargo, no hay evidencia alguna de mordeduras en su esqueleto. Probablemente su caída a la sima es posterior a la de los demás perros.

Los perros $n^{\circ} 1$ (Figura 35) y $n^{\circ} 2$ han sobrevivido al perro $n^{\circ} 3$ ya que no presentan evidencias de mordeduras en sus esqueletos mientras que este último ha sido parcialmente comido. Del perro $\mathrm{n}^{\circ} 4$ no se puede decir nada al respecto ya que sólo se conserva el cráneo.

\subsection{Cerdos}

Hay restos de dos individuos distintos que conservan tan sólo parte del esqueleto tanto craneal como postcraneal.

\section{Cerdo $n^{\circ} 1$}

Se trata de un individuo del que se conservan 16 restos (Tabla 8 ).

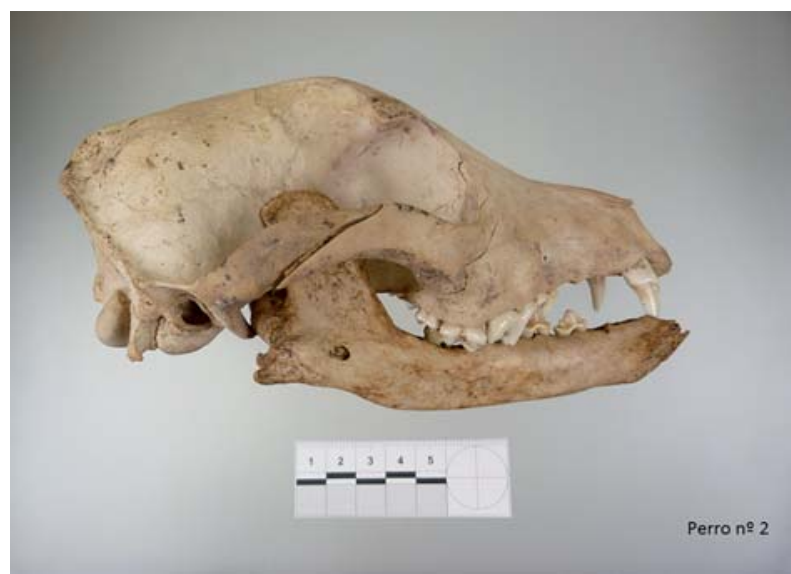

Fig. 35. Cráneo del perro número 2 (norma lateral derecha). / Skull of dog number 2 (right norma lateralis).

\begin{tabular}{|l|l|}
\hline Hueso & NR \\
\hline Cráneo & 2 \\
\hline Mandíbula & 3 \\
\hline Vértebras & 3 \\
\hline Escápula & 2 \\
\hline Húmero & 2 \\
\hline Fémur & 2 \\
\hline Peroné & 1 \\
\hline Falange 2 & 1 \\
\hline TOTAL & 16 \\
\hline
\end{tabular}

Tabla 8: Índice de robustez (IR) y altura en la cruz (AC). / Robustness index (RI) and crossover height $(\mathrm{CH})$.

Los dos húmeros tienen sin fusionar tanto la epífisis proximal como la distal. Las escápula presentan huellas de mordeduras. Los caninos indican que se trata de una hembra. Está presente el primer molar definitivo pero el segundo aún no ha erupcionado. Por tanto se trata de un ejemplar cuya edad oscila entre los 6 y los 8 meses.

\section{Cerdo $n^{\circ} 2$}

Este segundo ejemplar sólo conserva una docena de huesos (Tabla 9).

\begin{tabular}{|l|l|}
\hline Hueso & NR \\
\hline Cráneo & 7 \\
\hline Vértebras & 1 \\
\hline Escápula & 1 \\
\hline Pelvis & 1 \\
\hline Fémur & 2 \\
\hline TOTAL & 12 \\
\hline
\end{tabular}

Tabla 9: Restos del cerdo $n^{\circ} 2$. / Remains of pig $n^{\circ} 2$.

Los dos fémures tienen sin fusionar las epífisis distales y la vértebra dorsal presenta las superficies intervertebrales también sin fusionar. En la dentadura superior los caninos indican que se trata de una hembra. Están presentes los dos primeros molares y los premolares definitivos pero el tercer molar aún no ha erupcionado por lo que se le puede estimar una edad que oscila entre 18 y 20 meses.

\subsection{Ovejas}

Se conservan restos de dos ovejas adultas (ambas hembras) y de un individuo juvenil cuyo sexo no puede determinase. Faltan muchos elementos del esqueleto en los tres ejemplares. Sólo se aprecian signos de mordeduras en el fémur y en la mandíbula. En una costilla se observa una fractura consolidada.

\subsection{Equido}

Hay un conjunto de vértebras (una lumbar, una caudal y 16 dorsales) que corresponden a un équido. Es difícil establecer si se trata de un caballo de pequeño tamaño o de un asno.

No se aprecian señales de mordeduras. En las apófisis neurales de algunas vértebras dorsales se aprecian claras exóstosis.

La muestra se completa con la presencia de una herradura que pudiera corresponder al équido. 


\subsection{Conclusiones al análisis de los restos faunísticos}

El análisis de la fauna recuperada en la sima de El Raso de Urbasa junto a restos humanos, corresponde a un mínimo de cinco perros, dos cerdos, tres ovicaprinos y un équido. La presencia de los herbívoros en la sima puede ser consecuencia por una parte de la caída accidental de animales (sobre todo jóvenes) en la misma ya que en el entorno hay piaras de cerdos y rebaños de ovejas que se mueven con libertad. Sin embargo, no se puede descartar el uso de la sima por parte de pastores como muladar al que se arrojan animales enfermos o muertos por otras causas. Esto pudiera explicar la presencia del équido puesto que se trata de un ejemplar viejo a juzgar por las exóstosis que presenta en las vértebras.

Más interesante resulta la presencia de perros si se tiene en cuenta que parte de los restos humanos ha sido parcialmente consumida por estos carnívoros. Se han podido identificar cinco individuos distintos. Uno de ellos (perro $n^{\circ} 5$ ) es un individuo de 4-5 meses cuyos parámetros osteométricos sólo tienen valor relativo ya que no ha finalizado su configuración cefálica ni el crecimiento de los huesos largos. Su presencia en la sima quizás fuera posterior a la de los restos humanos.

Los otros cuatro perros (tres hembras y un macho adultos) presentan rasgos morfométricos similares por lo que puede suponerse que pertenecen al mismo tipo racial. Se trata de individuos meso-braquicéfalos, con oclusión normal entre las series dentarias superior e inferior que presentan divergencia entre la longitud craneal y la del hocico. Tres de ellos presentan alzadas por debajo de $500 \mathrm{~mm}$ y sus huesos son gráciles. Es difícil la adscripción a una raza concreta sólo a partir del esqueleto. En este caso y con los datos disponibles, sería un tipo de perro similar al pastor vasco o al Sabueso que ha sido muy común en la Península Ibérica.

Parece que los tres primeros son coetáneos de los restos humanos, consumiendo parcialmente los cadáveres tal como indica la profusión de excrementos, la falta de falanges humanas y las evidencias en los huesos humanos. Hay también evidencias de consumo entre los propios perros en el individuo $n^{\circ}$ 3. Sin embargo, resulta difícil de explicar cómo acceden al fondo de la sima teniendo en cuenta la profundidad de la misma. No se puede descartar la hipótesis de que fueran depositados en la cavidad de manera intencionada, pero tampoco hay pruebas fehacientes de ello.

\section{CONCLUSIONES}

A través del análisis de los restos humanos y de la fauna recuperados en la sima El Raso de Urbasa (Navarra) se ha podido conocer y constatar los relatos históricos y los testimonios aportados por los familiares de las diez personas, vecinos de Eulate, Etxarri-Aranaz y Zegama, que fueron ejecutadas en tres fechas de los meses de agosto y septiembre de 1936, durante Guerra Civil, en la época de violencia y represión más intensa. Se trata, de hecho, de represión ejercida contra población civil lejos del contexto bélico. Las ejecuciones se cometieron en la explanada El
Raso y los cadáveres fueron después arrojados por la boca de la sima para su ocultamiento. En el interior de la misma también se localizaron varios perros que, posiblemente, fueron descendidos ya que no presentan fracturas como consecuencia de la caída. Al menos, tres de los cinco perros sobrevivieron un tiempo más o menos prolongado gracias a la práctica del carroñeo y al consumo de restos humanos. Los pastores de la zona recordaban que se escuchaban ruidos y movimientos en el interior de la sima los días posteriores a los asesinatos.

\section{AGRADECIMIENTOS}

Los autores agradecen a los familiares de las víctimas la confianza depositada en esta investigación y de forma concreta a Balbino García de Albizu, que ha actuado como coordinador y mediador en las gestiones necesarias para realizar esta investigación.

\section{BIBLIOGRAFÍA}

AFAN

2004 Navarra 1936 de la esperanza al terror. Altaffaylla. Tafalla.

ALONSO, A.

2006 La identificación genética de las víctimas de la Guerra Civil española, en ARMH La represión franquista: mito, olvido y memoria. 183-193. Universidad de Valladolid. Valladolid.

ANDREA, A.C. \& GOTTHARDT, R.M

1984 Predator and Scavenger Modification of Recent Equid Skeletal Assemblages. Arctic 3, 275-283.

AUFDERHEIDE, A.C. \& RODRÍGUEZ-MARTíN, C.

1998 Human Paleopathology. Cambridge University Press.

AZNAR, J.M., CELORRIO, D., ODRIOZOLA, A., KOHNEMANN S., BRAVO, M.L. et al.

2014 I-DNASE21 system: development and SWGDAM validation of a new STR 21-plex reaction. Forensic Sci Int Genet 8, 10-19.

BASS, W.M.

1971 Human Osteology. Missouri Archaeological Society. Special publication n. 2. Columbia. Missouri.

BUIKSTRA, J. \& UBELAKER, D.

1994 Standards for data collection from human skeletal remains. Arkansas Archaeol. Survey.

CARDOSO, S., VILLANUEVA-MILLAN, M.J., VALVERDE, L., ODRIOZOLA, A., AZNAR, J.M. et al.

2012 Mitochondrial DNA control region variation in an autochthonous Basque population sample from the Basque Country. Forensic Sci Int Genet 6, e106-108.

DIMAIO, VJM.

1985 Gunshot wounds: Practical aspects of firearms, ballistics, and forensic taphonomy. Elsevier. New York. 
DRIESCH, A.v.d.

1976 Das Vermessen von Tierknochen aus vor und frühgeschichtliche Siedlunge. München.

\section{ETXEBERRIA, F.}

2004 Panorama organizativo sobre Antropología y Patología Forense en España. Algunas propuestas para el estudio de fosas con restos humanos de la Guerra Civil española de 1936, en La memoria de los olvidados. Un debate sobre el silencio de la represión franquista. 183-219. Edit. Ámbito.

2012 Exhumaciones contemporáneas en España: las fosas comunes de la Guerra Civil. Boletín Galego de Medicina Legal e Forense 18, 13-28.

\section{ETXEBERRIA, F. y CARNICERO, M.A.}

1998 Estudio macroscópico de las fracturas del perimortem en Antropología Forense. Study macroscopic of the fractures made in the perimortem of Forensic Anthropology. Revista Española de Medicina Legal 84-85, 36-44.

ETXEBERRIA, F., HERRASTI, L., PUENTE, J., BANDRES, A., JIMENEZ, J. y PERES DE LA IGLESIA, L.

2010 Exhumación y análisis de los restos humanos recuperados en una fosa común del cementerio de Tudela (Navarra). Munibe Antropologia-Arkeologia 61, 395-406.

ETXEBERRIA, F., SERRULLA, F. y HERRASTI, L.

2014 Simas, cavernas y pozos para ocultar cadáveres en la Guerra Civil española (1936-1939. Aportaciones desde la Antropología Forense. Munibe Antropologia-Arkeologia 65, 269-288.

ETXEBERRIA, F., HERRASTI, L., PÉREZ DE LA IGLESIA, L., ALBISU, C., JIMÉNEZ, J., CARDOSO, S., BAETA, M., NUÑEZ, C., PALENCIA, L. y MARTÍNEZ DE PANCORBO, M.

2012 Exhumación, identificación y causa de muerte en la fosa común de Aibar-Oibar (Navarra). Munibe AntropologiaArkeologia 63, 367-377.

GÓMEZ, M.

1994 El Euskal Artzain Txakurra (Perro de Pastor Vasco): una "joya" de nuestra tierra. Adecap 9, 45-47.

GUSMAO, L., SANCHEZ-DIZ, P., ALVES, C., GOMES, I., ZARRABEITIA, M.T. et al.

2009 A GEP-ISFG collaborative study on the optimization of an X-STR decaplex: data on 15 Iberian and Latin American populations. International Journal of Legal Medicine 123, 227-234.

HAGLUND, W.D., REAY, D.T. y SWINDLER, D.R.

1988 Tooth Mark Artifacts and Survival of Bones in Animal Scavenged Human Skeleton. Journal of Forensic Sciences 33, 985-997.

1989 Canid Scavenging/Disarticulation Sequence of Human Remains in the Pacific Northwest. Scavenged Human Skeleton. Journal of Forensic Sciences 34, 587-606.

\section{HARCOURT, R.A.}

1974 The Dog in Prehisthoric and Early Historic Britain. Journal of Archaeological Science 1, 151-175.

ISIDRO, A. y MALGOSA, A.

2003 Paleopatología. La enfermedad no escrita. Masson.
KIMMERLE, E.H. y BARAYBAR, J.P.

2011 Traumatismos óseos. Lesiones ocasionadas por violaciones a los Derechos Humanos y conflictos armados. Lima.

KROGMAN, WM. \& ISCAN, YM.

1986 The Human Skeleton in Forensic Medicine. Ch. C. Thomas Ed. Springfield, Illinois.

\section{MORAITIS, K. \& SPILIOPOULOU, CH.}

2010 Forensic implications of carnivore scavenging on human remains recovered from outdoor locations in Greece. Journal of Forensic and Legal Medicine 17, 298-303.

\section{ORTNER, D.J.}

2003 Identification of Pathological Conditions in Human Skeletal Remains. Academic Press.

PRADA, E., ETXEBERRIA, F., HERRASTI, L., VIDAL, J., MACÍAS, S. Y PASTOR, F.

2003 Antropología del pasado reciente: una fosa común de la Guerra Civil española en Priaranza del Bierzo (León), en ALUJA, M.P., MALGOSA, A. Y NOGUÉS, R.M.(Coor.). Antropología y Biodiversidad Volumen I. 431-446. Ediciones Bellaterra. Barcelona.

PRIETO-FERNÁNDEZ, E., BAETA, M., NÚÑEZ, C., JIMÉNEZ-MORENO, S. \& M. DE PANCORBO, M.

2015 A new 17 X-STR multiplex for forensic purposes. Forensic Sci Int Genet Supplem. (in press).

PRINZ, M., CARRACEDO, A., MAYOR, W.R., MORLING, N., PARSONS, T.J., SAJANTILA, A. et al.

2007 DNA Commission of the International Society for Forensic Genetics (ISFG): recommendations regarding the role of forensic genetics for disaster victim identification (DVI). Forensic Science International Genetic 1, 3-12.

REVERTE, J.M.

1999 Antropología Forense. Ministerio de Justicia. Madrid.

\section{RODRÍGUEZ, J.V.}

1994 Introducción a la Antropología Forense. Análisis e interpretación de restos óseos humanos. Anaconda Editores. Santa Fe de Bogotá

STEADMAN, D.W. \& WORNE, H.

2007 Canine scavenging of human remains in an indoor setting. Forensic Science International 173, 78-82.

UBELAKER, D.

2007 Enterramientos humanos. Excavación, análisis, interpretación. Munibe. Suplemento 24.

WEDEL, V.L. \& GALLOWAY, A.

2014 Broken Bones: Anthropological Analysis of Blunt Force Trauma. Charles C. Thomas Publisher.

WILLEY, P. \& SNYDER, L.M.

1989 Canid Modification of Human Remains: Implications for Time-Since-Death Estimations. Journal of Forensic Sciences 34, 894-901. 